\title{
Comparative Multidimensional Molecular Analyses of Pediatric Diffuse Intrinsic Pontine Glioma Reveals Distinct Molecular Subtypes
}

\author{
Amanda M. Saratsis ${ }^{1,2}$, Madhuri Kambhampati ${ }^{2}$, Kendall Snyder $^{2}$, Sridevi Yadavilli $^{2}$, Joe \\ Devaney $^{2,3}$, Brennan Harmon ${ }^{2}$, Jordan Hall ${ }^{2}$, Eric H. Raabe ${ }^{4,5}$, Ping An ${ }^{4,6}$, Melanie \\ Weingart $^{4}$, Brian R. Rood ${ }^{7}$, Suresh Magge ${ }^{8}$, Tobey J. MacDonald ${ }^{9}$, Roger J. Packer ${ }^{10,11}$, \\ and Javad Nazarian ${ }^{2,3}$ \\ ${ }^{1}$ Department of Neurosurgery, Georgetown University Hospital, Washington DC, 20007, USA \\ ${ }^{2}$ Center for Genetic Medicine, Children's National Medical Center, Washington DC, 20010, USA \\ ${ }^{3}$ Department of Integrative Systems Biology, George Washington University School of Medicine \\ and Health Sciences, Washington, DC, 20052, USA \\ ${ }^{4}$ Division of Neuro-Pathology, Johns Hopkins University School of Medicine, Baltimore MD \\ 21287, USA \\ ${ }^{5}$ Division of Pediatric Oncology, Johns Hopkins University School of Medicine, Baltimore MD \\ 21287, USA \\ ${ }^{6}$ Neurobiology Department, College of Basic Medical Sciences, China Medical University, \\ 110001, China \\ ${ }^{7}$ Division of Oncology, Center for Cancer and Immunology Research, Children's National Medical \\ Center, Washington DC, 20010, USA \\ ${ }^{8}$ Division of Neurosurgery, Children's National Medical Center, Washington DC, 20010, USA \\ ${ }^{9}$ Department of Pediatrics, Emory University School of Medicine, Atlanta, GA, 30322, USA \\ ${ }^{10}$ Division of Neurology, Center for Neuroscience Research, Children's National Medical Center, \\ Washington DC, 20010, USA \\ ${ }^{11}$ Brain Tumor Institute, Center for Neuroscience and Behavioral Medicine, Children's National \\ Medical Center, Washington DC, USA
}

\section{Abstract}

Diffuse Intrinsic Pontine Glioma (DIPG) is a highly morbid form of pediatric brainstem glioma. Here, we present the first comprehensive protein, mRNA, and methylation profiles of fresh frozen DIPG specimens $(n=14)$, normal brain tissue $(n=10)$, and other pediatric brain tumors $(n=17)$. Protein profiling identified 2,305 unique proteins indicating distinct DIPG protein expression

Corresponding Author: Javad Nazarian, Children's National Medical Center, Center for Genetic Medicine, 111 Michigan Ave., NW, Washington DC, 20010, Phone: 202-476-6022, Fax: 202-476-6014, JNazarian@ChildrensNational.org. 
patterns compared to other pediatric brain tumors. Western blot and immunohistochemistry validated upregulation of Clusterin (CLU), Elongation Factor 2 (EF2), and Talin-1 (TLN1) in DIPGs studied. Comparisons to mRNA expression profiles generated from tumor and adjacent normal brain tissue indicated two DIPG subgroups, characterized by upregulation of Myc (N$\mathrm{Myc}$ ) or Hedgehog (Hh) signaling. We validated upregulation of PTCH, a membrane receptor in the Hh signaling pathway, in a subgroup of DIPG specimens. DNA methylation analysis indicated global hypomethylation of DIPG compared to adjacent normal tissue specimens, with differential methylation of 24 genes involved in Hh and Myc pathways, correlating with protein and mRNA expression patterns. Sequencing analysis showed c.83A>T mutations in the H3F3A or HISTIH3B gene in $77 \%$ of our DIPG cohort. Supervised analysis revealed a unique methylation pattern in mutated specimens compared to the wild type DIPG samples.

This study presents the first comprehensive multidimensional protein, mRNA, and methylation profiling of pediatric brain tumor specimens, detecting the presence of two subgroups within our DIPG cohort. This multidimensional analysis of DIPG provides increased analytical power to more fully explore molecular signatures of DIPGs, with implications for evaluating potential molecular subtypes and biomarker discovery for assessing response to therapy.

\section{Keywords}

Diffuse Intrinsic Pontine Glioma (DIPG); Brainstem Glioma; Proteomics; Histone H3; Myc Oncogene; Hedgehog

\section{Introduction}

Brain tumors are the most common solid tumor in children. Approximately $15 \%$ occur in the brainstem where up to $80 \%$ are diffuse intrinsic pontine glioma (DIPG). DIPG affects young children with onset between 6 and 9 years of age [53]. Radiation therapy is the standard treatment, temporarily decreasing symptoms, yet DIPG continues to exhibit the highest mortality rate of all pediatric brain tumors with median survival less than 12 months and 5year survival rate less than five percent [16]. Despite almost 40 years of clinical trials exploring chemotherapeutic and radiation regimens, there has been little change in treatment paradigm or overall survival for children with DIPG [4,16,24].

DIPG is an infiltrative, often high-grade (WHO III or IV) astrocytoma (HGA) of the brainstem and is not amenable to surgical resection. Diagnosis is commonly made at the time of symptom onset based on characteristic radiographic appearance on magnetic resonance imaging (MRI), and diagnostic tissue biopsy is uncommonly performed [16,53]. Historically, this resulted in poor access to tumor tissue for molecular analysis, hindering understanding of tumor biology and development of therapeutic modalities to improve survival. The cooperation of tumor consortiums, relative increase in the safety and frequency of stereotactic tumor biopsy, and postmortem tissue collection have facilitated recent molecular analyses of rare DIPG tissue specimens [2,4,8,24,37]. These studies demonstrate that DIPGs exhibit distinct molecular characteristics compared to HGAs, and that DIPG represents a biologically heterogeneous group of brainstem tumors with clinical implications [3,6,20,33,36,38,43,47,49,58]. In addition, missense mutations Lys27Met 
(K27M) and Gly34Arg/Val (G34R/V) in genes encoding Histone H3.3 (H3F3A) and H3.1 $(H I S T 3 H 1 B)$ have recently been identified in pediatric gliomas, and the H3 K27M driver mutation correlated with a clinically and biologically distinct subgroup of DIPG patients $[26,27,45]$. This underscores the need for improved molecular characterization of DIPG using clinically accessible tissue specimens and cutting-edge techniques for accurate diagnosis and improved patient outcomes.

We previously performed protein profiling of archival formalin fixed paraffin embedded (FFPE) postmortem tumor specimens, demonstrating the utility of proteomic analysis of cerebrospinal fluid (CSF) from patients with DIPG for detection of tumor-secreted proteins as biomarkers for clinical diagnosis and treatment $[34,43]$. To expand our analyses, we performed a multidimensional study of rare fresh frozen DIPG specimens to characterize protein, mRNA, and methylation patterns in a cohort of pediatric brain tumor specimens, including DIPGs $(\mathrm{n}=14)$ for which histone 3 mutation status was also investogated. Our mRNA and protein profiles suggest the presence of two subgroups within our DIPG cohort representing Myc and Hh signaling pathways. We validate upregulation of Patched (PTCH) wtih nuclear translocation of Glioma Associated Oncogene 1 (GLI1), two key Hh pathway molecules, as well as expression of Clusterin (CLU), Talin-1 (TLN1), and Elongation Factor 2 (EF2) proteins in DIPG tumor tissue. Our methylation analysis indicated hypomethylation of DIPG, while supervised clustering of methylation profiles based on Histone H3.3 K27M mutation status showed differential methylation patterns between mutant and wild type tumors affecting pathways of gene expression. To our best knowledge, this is the first comprehensive, multidimensional analysis of a cohort of pediatric brainstem glioma specimens.

\section{Materials and Methods}

\section{Biological Specimens}

A total of 44 tumor and normal brain tissue specimens (brainstem, cerebellum and frontal lobe) were collected in accordance with Children's National Medical Center Institutional Review Board (IRB) approvals (IRB\# 1339, \#463 and \#747) (Table 1). Patient identifiers were removed prior to evaluation and a single sequential numerical identifier (Patient ID, or PID) was assigned to each patient. All brain tumor diagnoses were made by a neuroradiologist based on radiographic imaging, and confirmed by neuropathologic evaluation of tissue specimens. Tumor and normal brain tissue was collected from 31 patients intraoperatively or postmortem, including postmortem DIPG $(n=14)$, supratentorial astrocytoma $(n=8)$, ependymoma $(n=3)$, infratentorial juvenile pilocytic astrocytoma $(n=2)$, medulloblastoma $(n=2)$, glioneural tumor $(n=1)$ or meningioma $(n=1)$. Normal tissue was obtained from perilesional brainstem $(n=8)$ or from normal frontal lobe $(n=4)$.

\section{Proteomic Analysis}

Protein $(30 \mu \mathrm{g})$ was obtained from each tissue sample, and resolved on SDS-Polyacrylamide gel electrophoresis as previously described [43]. Briefly, protein bands were sliced and processed for in-gel digestion and extraction and resolved using Eksigent nano-hplc system (Dublin, CA) and analyzed using mass spectrometery (ThermoFisher Scientific, Waltham, 
MA). MS data were searched using the Sequest algorithm in the Bioworks Browser 3.3.1 against the Uniprot human database. Search result files were loaded into ProteoIQ software (NuSep, Bogart, GA) and filtered based on the following stringent filtration criteria: $\geq 2$ peptides/protein, $\geq 10$ spectra/protein, minimum peptide probability-based score with a $\mathrm{p}$ value of $\leq 0.05$ and a variable threshold of Xcorr versus charge state $(X \operatorname{corr}=1.9$ for $\mathrm{z}=1$, $X \operatorname{corr}=2.5$ for $\mathrm{z}=2$, and $X \operatorname{corr}=3.5$ for $\mathrm{z}=3$ ). Protein expression analysis was performed with Partek Genomics Suite v6.6 (Partek Incorporated, St. Louis, MO).

\section{Antibodies}

Mouse monoclonal anti-TLN antibody (Santa Cruz Biotechnology, Santa Cruz, CA) was used at 1:100 dilution. Mouse monoclonal anti-CLU antibody (Abnova, Taipei City, Japan) was diluted 1:2000. Rabbit polyclonal anti-EF2 antibody (Lifespan Biosciences Inc., Seattle, WA) was diluted 1:1000. Horseradish peroxidase-labeled secondary antibodies were diluted 1:5000 (Kirkergaard and Perry Laboratories, Gaithersburg, MD). Rabbit polyclonal antiPTCH antibody (Abcam, Cambridge MA) was diluted 1:100. Rabbit polyclonal anti-ATRX antibody (Sigma Aldrich, St. Louis, MO) was diluted 1:200. Rabbit monoclonal anti-P53 antibody (Biocare Medical, Concord, CA) was prediluted ready to use. Rabbit anti-GLI1 polyclonal antibody (Gene Tex, Irvine, CA) was diluted 1:250. All antibodies used for Western blotting have been previously shown to detect the target protein at the correct molecular mass $[25,32,39,42]$.

\section{RNA extraction, reverse transcription and array hybridization}

Tissue specimens were homogenized in Trizol followed by phase-separation of nucleic acids with Chloroform. RNA was extracted using the Picopure RNA isolation kit (Arcturus Bioscience, Mountain View, CA). DNA was removed by treating columns with RNaseFree DNase (Qiagen, Valencia CA). RNA integrity and concentration was quantified using 2100 Bioanalyzer (Agilent Technologies, Santa Clara, CA).

The TotalPrep-96 RNA amplification kit (Illumina, Dan Diego, CA) was used for cRNA synthesis. cRNA was hybridized to whole-genome Human HT-4 v12 Gene Expression Bead Chips (Illumina, San Diego, CA), and bead fluorescence intensity detected using the HiScan SQ BeadArray Reader (Illumina, San Diego, CA). Gene expression data was analyzed with the GenomeStudio integrated informatics platform (Illumina, San Diego, CA) and Partek Genomics Suite v6.6 (Partek Incorporated, St. Louis, MO).

\section{Sanger Sequencing for Detection of H3F3A and HIST1H3B Mutation}

500ng of RNA was used for cDNA synthesis using the Applied Biosystems High Capacity cDNA Reverse Transcription kit (Life Technologies, Carlsbad, CA). The H3F3A and HISTIH3B genes were sequenced for the entire coding transcript. PCR was performed using Taq DNA polymerase (Invitrogen, Life Technologies, Carlsbad CA) and standard conditions using a $\mathrm{C} 1000$ Thermocycler (Biorad, Hercules, CA) with the following primers: $H 3 F 3 A$ forward primer 5'-ATGGCTCGTACAAAGCAG, reverse primer 5'ACCAGGCCTGTAACGATGAG. HISTIH3B forward primer 5'ATGGCTCGTACTAAACAGAC, reverse primer 5'-AGTCTTGGGCGATTTCTCG. A $1 / 10$ aliquot of the PCR products was run on an agarose gel to verify amplification of a 
single band, and the remainder was passed through a MinElute PCR-purification kit (Qiagen, Gaithersburg, MD). PCR products were sent for direct Sanger sequencing at the Johns Hopkins Genetic Research Core Facility, and sequence chromatograms were analyzed visually to detect $H 3 F 3 A$ and $H I S T I H 3 B$ c.83A>T mutations.

\section{DNA extraction and methylation analysis}

DNA (500 ng) was obtained from tissue lysates using the Gentra Puregene DNA Extraction kit (Qiagen, Valencia CA). DNA was prepared for methylation analysis via bisulphite conversion using the EZ DNA Methylation-Gold kit (Zymo Research, Irvine CA). Bisulphite converted DNA was denatured and neutralized. After amplification via PCR, DNA was fragmented and hybridized onto the Infinium HumanMethylation450BeadChip (Illumina, San Diego, CA) and quantified using the iScan Reader (Illumina, San Diego, CA). DNA methylation data was analyzed using GenomeStudio (Illumina, San Diego, CA) and Partek Genomics Suite v6.6 (Partek Incorporated, St. Louis, MO).

\section{Statistical Analysis}

Analyses were performed with Partek Genomics Suite v6.6 (Partek Incorporated, St. Louis, $\mathrm{MO})$. Protein and gene expression values in tumor tissue were normalized and compared to control specimens from the same patient: $p$-value $<0.05$ and fold change (FC) of expression $\leq 2$ or $\geq 2$ compared to normal tissue were considered significant (1-way ANOVA model by using Method of Moments [14]: Model: Yij $=\mu+$ Experimental Group i+ $\mathrm{ij}$, where Yij represents the jth observation on the ith Experimental Group, $\mu$ is the common effect for the whole experiment, and $\varepsilon i j$ represents the random error present in the jth observation on the ith Experimental Group. The errors eij are assumed to be normally and independently distributed with mean 0 and standard deviation $\delta$ for all measurements. Fisher's Least Significant Difference (LSD) contrast method was performed to compare groups [1]. For patients from whom normal tissue was not available, comparisons were conducted using normalized values for all tumor and normal specimens and filtered for significance (ANOVA, $p$-value $<0.05$ and FC $\leq 2$ or $\geq 2$ ). DNA methylation profiles compared between tumor and normal specimens from the same patient (ANOVA, $p$-value $<0.05$ and FC $\leq 3$ or $23)$.

\section{Results}

\section{Proteomic Analysis of Pediatric Brain Tumor Specimens}

A total of 44 fresh frozen pediatric brain tissue specimens were used for label-free proteomic analysis (Table 1). Tumor specimens included DIPG $(n=14)$, supratentorial astrocytoma $(n=8)$, ependymoma $(n=3)$, infratentorial juvenile pilocytic astrocytoma $(n=2)$, medulloblastoma $(n=2)$, glioneural tumor $(n=1)$, and meningioma $(n=1)$. For comparison, normal perilesional brainstem tissue from DIPG patients $(\mathrm{n}=8)$, and normal frontal lobe tissue from DIPG $(n=2)$ and supratentorial pediatric GBM $(n=2)$ patients were also collected. Unsupervised clustering of all tumor protein profiles grouped DIPGs distinctly and closest to supratentorial HGAs (Online Resource 1). Unsupervised clustering and principle component analysis of high-grade glioma protein profiles (supratentorial pediatric GBM and DIPG) demonstrated clustering by tumor location and Histone 3 mutation status 
(Fig. 1a). A total of 2,305 unique proteins were detected across all specimens, with an average of 1,155 proteins detected per specimen (protein expression data provided in Online Resource 1-6).

Amongst DIPG tumor specimens $(n=14)$, a total of 2,061 proteins were positively identified (Online Resource 2) of which 1,744 (79.4\%) proteins were detected in both normal and tumor tissue from DIPG patients [317 (14.4\%) proteins unique to tumor and $135(6.1 \%)$ unique to normal]. Unsupervised hierarchical clustering of pairwise DIPG protein profiles revealed the presence of two subgroups in our cohort, termed Subgroups 1 and 2 (Online Resource 3). A total of 65 proteins were significantly differentially expressed between these two subgroups (ANOVA, $p$-value $<0.05$ and FC $\leq 2$ or $\geq 2$, Online Resource 4).

Protein profiles of fresh frozen DIPG specimens were compared to previously characterized CSF [43] and paraffin embedded DIPG profiles [34] (Online Resource 5). A large percentage of the DIPG CSF proteome $(76.8 \%)$ was detected in fresh frozen DIPG tissue. A total of $75 \%$ (42 of 55) of proteins previously identified by our group in paraffin embedded DIPG tumor tissue (FFPE) [34] were also detected in the fresh frozen DIPG tumor tissue analyzed here.

\section{Validation of Proteomics Data}

CLU, EF2, and TLN1 were selected for further validation based on their expression profiles and biological functions. We validated upregulation of CLU and TLN1 in tumor by Western blotting assays (Fig. 1b). EF2 expression was observed in only one of the two DIPG specimens and none of the two adjacent normal tissue specimens tested (Fig. 1b). Immunohistochemical staining of DIPG tumor and perilesional normal brainstem tissue further confirmed tumor-specific expression of CLU, EF2, and TLN1 (Fig. 1b). Antibody specificity was validated by mass spectrometry: protein profiles were searched to ensure that detected bands on Western blot correlated to peptides identified by mass spectrometry for the target protein at the same molecular mass (Online Resource 6).

\section{mRNA Expression Profiling of Pediatric Brain Tumor Specimens}

Tissue mRNA expression of 16 high-grade astrocytoma (HGA) specimens, including DIPG $(n=13)$ and supratentorial pediatric GBM $(n=3)$, were characterized and compared to normal tissue profiles from the same patients $(n=10)$. mRNA profiles of low grade astrocytoma $(n=3)$, ependymoma $(n=3)$, infratentorial juvenile pilocytic astrocytoma $(n=2)$, medulloblastoma $(n=2)$, meningioma $(n=1)$, and glioneural tumor $(n=1)$ tissue were also characterized (Online Resources 7-11). A total of 1,249 differentially expressed genes were identified between tumor and normal tissue (ANOVA, $p$-value Dx $<0.05$ and FC $\leq 2$ or $\geq 2$, Online Resource 7). As with protein profiles, unsupervised clustering of all tumor mRNA profiles grouped DIPGs distinctly and closest to supratentorial HGAs (Online Resource 8). Unsupervised analysis of HGA mRNA expression profiles (pediatric supratentorial GBM $\mathrm{n}=1$, and DIPG $\mathrm{n}=8$ ) revealed clustering by tumor location and Histone 3 mutation status (Online resource 9). Comparative mRNA expression in eight DIPGs was evaluated via pairwise comparison with normal perilesional brainstem $(n=6)$ or frontal lobe tissue $(n=2)$ from the same patient (Online Resource 10), yielding 1,918 differentially expressed genes 
(ANOVA, $p$-value $<0.05$ and FC $\leq 2$ or $\geq 2$, results provided in Online Resource 11). Unsupervised hierarchical clustering of pairwise gene expression profiles revealed two distinct DIPG subgroups (Subgroups 1 and 2, Fig. 1c), validating clustering of protein profiles with the exception of the two tumor specimens normalized to frontal lobe tissue (Patient IDs 13 and 14), which clustered with Subgroup 2 at the protein level, but with Subgroup 1 at the mRNA level. Further analysis using Partek Genomics Suite (St. Louis, MO) revealed 158 most differentially expressed genes between these two subgroups (ANOVA, $p$-value $<0.05$ and FC $\leq 2$ or $\geq 2$ ), including CP, HIST1H4A, MMP17, LAMB1, LAMC1, NRCM, PDGFC, STMN, TMEM158, TNC, VAT1 and ZYX (Online Resource 12). Biologic differences between these subgroups were explored further through functional pathways analysis.

\section{Comparison of DIPG Protein and mRNA Expression Profiles}

To determine the overlap between gene and protein data sets, relative gene and protein expression profiles between tumor and normal tissue of the same (pairwise) DIPG patients $(\mathrm{n}=8)$ were compared. A total of 2,305 distinct proteins were identified in tissue proteomic analysis, with 2,215 of these detected at the mRNA level, representing $96 \%$ of the total detected tissue proteome. Of the molecules detected in both analyses, $54 \%$ exhibited concordant expression patterns (i.e. up or down regulated at both the mRNA and protein level) (Fig. 1c). Differences in mRNA and protein profiles could be attributed to relative instability and higher rate of turnover of mRNA compared to protein. Focused analysis of DIPG protein profiles limited to only those patients for which mRNA profiling was also performed $(n=8)$ revealed 65 differentially expressed proteins $(p \unlhd 0.05)$ between Subgroups 1 and 2 (ANOVA, $p$-value $<0.05$ and $\mathrm{FC} \leq 2$ or $\geq 2$ ) (Fig. 1c).

Observed DIPG mRNA and protein expression profiles were used to explore molecular pathways of DIPG tumorigenesis using IPA software. Actin cytoskeletal signaling and axonal signaling were identified as the top canonical pathways represented by both protein and gene profiles (pathway depicted in Online Resource 13). Molecules in these pathways include CLU and TLN1 which we have shown to be upregulated in DIPG CSF [43].

\section{Characterization of DIPG Molecular Subtypes}

To explore molecular pathways underlying identified DIPG subgroups 1 and 2, IPA software was employed using observed pairwise mRNA and protein profiles. A significant difference in Myc Oncogene and Hh pathway activity was detected between Subgroups 1 and 2 at both mRNA and protein levels. Subgroup 1 showed increased Myc and Subgroup 2 exhibited increased $\mathrm{Hh}$ activity. Significant differential expression of downstream genes belonging to the Myc and Hh pathways were identified between the two subgroups (ANOVA, $p$-value $<0.05$ and FC $\leq 2$ or $\geq 2$ ) including: CDK1, COL1A2, DBI, GLI1, PTCH1, $M Y C N$, SMO, SOX18, STMN1, TNC, and VEGFA (ANOVA, $p$-value $<0.05$ and FC $\leq 2$ or

2) (Online resource 14-15).

Subsequent unsupervised analysis of expression values of genes belonging to Myc and Hh signaling pathways recapitulated the subgroup clustering patterns from the unsupervised mRNA analysis (Online Resource 15). 


\section{Functional Analysis Based on Histone H3 K27M Mutation}

Mutations in the H3F3A and HISTIH3B genes, which encode histone variants $\mathrm{H} 3.3$ and H3.1 respectively, have recently been implicated in pediatric DIPG and HGA [19,26,57]. We performed Sanger sequencing of the H3F3A and HISTIH3B loci on DNA extracted from our cohort of brain tumor specimens. We detected c.83A $\rightarrow \mathrm{T}$ missense mutation resulting in pLys27Met (K27M) substitution in 10 out of 13 (77\%) DIPG specimens (H3F3A mutation $\mathrm{n}=8, H I S T 1 H 3 B$ mutation $\mathrm{n}=2$ ). Histone mutations were also detected in GBM specimens ( $H 3 F 3 A$ mutation $\mathrm{n}=2$, HISTIH3B mutation $\mathrm{n}=1$ ) but not in tumor tissue from patients with ependymoma, low-grade supratentorial astrocytoma, medulloblastoma, infratentorial juvenile pilocytic astrocytoma, glioneural tumor, or meningioma (Online Resource 16).

To further explore the effect of Histone 3 mutation on molecular expression in DIPGs, we analyzed mRNA and protein profiles of HGA specimens based on tumor location and mutation status. Unsupervised analysis of HGA protein profiles (DIPG $n=14$, supratentorial pediatric GBM $n=4$ ) resulted in specimen clustering by Histone 3 mutation status, then location (Fig. 1a). Supervised analysis of HGAs by tumor location revealed 108 differentially expressed proteins between infratentorial (DIPG, $n=14$ ) and supratentorial (GBM, n=4) HGAs, and 60 significantly differentially expressed proteins between H3.3 mutants $(\mathrm{n}=10)$ and wild types $(\mathrm{n}=8)$. Functional analysis indicated relative decreased VEGF (activation z score -2.19, $p$-value 5.04×10E-3) vs. increased Myc (z-score 0.2, $p$-value $1.38 \times 10-3)$ signaling in infratentorial compared to supratentorial HGAs. Histone signaling was the top differentially activated pathway in $\mathrm{H} 3.3$ mutants, with differentially expressed molecules mapping to telomere extension ( $p$-value $2.22 \times 10 \mathrm{E}-2)$ and DNA methylation/ transcription repression signaling ( $p$-value $2.92 \times 10-2)$. Supervised analysis of DIPG $(n=14)$ protein profiles by Histone 3 mutation status revealed 112 proteins with significant differential expression between Histone 3 mutants (H3.3 n=8, H3.1 n=2, total n=10) and wild types ( $\mathrm{n}=4$ ) across all specimens (ANOVA, $p$-value $<0.05$ and FC $\leq 2$ or $\geq 2$ ) (Online resource 17). Further parsing by H3.1 versus H3.3 mutation status demonstrated 94 significantly differentially expressed proteins between H3.3 mutants and wild types, 59 between H3.1 mutants and wild types, and 54 between H3.3 and H3.1 mutants (ANOVA, pvalue $<0.05$ and FC $\leq 2$ or $\geq 2$ ) (data not shown). Functional analysis comparing DIPG Histone 3 mutant protein profiles to wild type specimens identified greater relative MYC activation in H3.3 compared to H3.1 mutants (z score 0.277 , $p$-value $3.7 \times 10 \mathrm{E}-2$ ).

Comparison of HGA mRNA profiles by tumor location revealed 2,274 significantly differentially expressed genes between DIPGs $(\mathrm{n}=13)$ and supratentorial GBMs $(\mathrm{n}=3)$ (ANOVA, $p$-value $<0.05$ and $\mathrm{FC} \leq 2$ or $\geq 2$ ), with $\mathrm{H} 3$ mutant profiles clustering distinctly from wild types (Online Resource 18). Supervised analysis of DIPG mRNA profiles based on H3.3 mutation status revealed 345 significantly differentially expressed genes (ANOVA, $p$-value $<0.05$ and FC $\leq 2$ or $\geq 2$ ) (Online Resource 19). A total of 58 genes were upregulated (FC $\geq 2)$ in all H3.3 K27M mutants with respect to wild type specimens. In contrast, 209 genes were downregulated (FC $\leq 2$ ) in all H3.3 K27M mutants (Online Resource 20). Supervised clustering of DIPG specimens based on H3 K27M mutation did not align with the Myc (Subgroup 1) and Hh (Subgroup 2) DIPG subgroups identified by mRNA and 
proteomics analysis (Online Resource 19). To further evaluate the relationship between observed Subgroups 1 and 2 and H3 mutation status, we selected DIPG specimens that contained both normal and tumor tissue, and that represent both the $\mathrm{H} 3$ mutation statuses as well as subgroup classifications (1 and 2). Three FFPE DIPG specimens met these criteria and were used to evaluate the expression of Patch1 (PTCH1), a transmembrane protein that acts as the receptor for Hedgehog (Hh). All tumor tissue demonstrated greater PTCH1 staining compared to adjacent perilesional normal tissue (Fig. 2a). As expected, the two specimens belonging to Subgroup 2 demonstrated greater PTCH1 staining than the Subgroup 1 specimen. To confirm activation of Hh signaling in Subgroup 2 patients, we performed immunohistochemistry to measure nuclear localization of GLI1 as a marker of downstream activation of Hh signaling in four DIPG tumor specimens. We detected nuclear localization of GLI1 in all three DIPG subgroup 2 specimens (Fig. 2b). In contrast, GLI1 nuclear expression and localization was not detected in the Subgroup 1 specimen tested. H3 mutation status did not seem to affect the level of PTCH1 or GLI1 expression, suggesting differential Hh pathway activity may be independent of H3 K27M mutation in these specimens. Immunohistochemical staining revealed low p53 expression in three $\mathrm{H} 3$ mutant DIPGs but not in the H3 wild type specimen (Fig. 2b). ATRX was not detected in any of the DIPG tissue specimens tested $(n=4)$, but was expressed in an adult GBM specimen stained as a positive control (Online Resource 21).

\section{Methylation Analysis of DIPG Tissue}

DNA methylation patterns were studied in nine pairs of DIPG tumor and adjacent perilesional normal brain tissue (Online Resources 22-23). Unsupervised Bayesian analysis exhibited greater genome-wide hypomethylation compared to normal tissue from the same patients with 4,808 CpG sites significantly hypermethylated and 14,428 hypomethylated (ANOVA, $p$-value with FDR $₫$ 0.05 and FC $\leq 3$ or $\geq 3$, Online Resource 22) (Fig. 3a). Pathways analysis implicated cellular receptor activity as top molecular function, and cell proliferation as top biological function of differentially methylated genes in tumor specimens.

Supervised analysis of methylation profiles comparing Subgroup 1 and 2 revealed 786 differentially methylated CpG loci (ANOVA, $p$-value with FDR $<0.05$ and FC $\leq 2$ or $\geq 2$ ) (Fig. 3b; filtered analysis results provided in Online Resource 24). Functional analysis of genes hypomethylated in Subgroup 1 (Myc) but hypermethylated in Subgroup 2 (Hh) demonstrated a network of molecular interaction including $M Y C$, AKT and PDGFBB, with telomerase signaling as the top canonical pathway ( $p$-value 1.04E-02). Hypomethylated Subgroup 2 genes represented a network of molecular interaction including $C D K N 1 B$, $W N T 7 A, W N T 3$ and $F O X F$, with cell cycle checkpoint regulation at G1/S as the top canonical pathway ( $p$-value 9.53E-03) (Online Resource 25). Network interaction with Histone 3 was identified in both sets of genes. Our analysis confirmed that in most cases methylation levels were concordant with detected relative gene and protein expression. For example, inspection of DNA methylation at $486 \mathrm{CpG}$ sites corresponding to genes involved in Myc or Hh signaling revealed differential methylation of 29 genes between Subgroup 1 and 2, including COL1A2, HIST1H4A, NOX4, LAMB1, LAMC1, MYC, TNF, TNC, GLIPR1, and $S R F$ (ANOVA, $p$-value $<0.05$ and FC $\leq 2$ or $\geq 2$ ) (Online resource 26). Unsupervised 
analysis of DNA methylation values for these genes yielded the same two DIPG subgroups identified in proteomic and mRNA analysis (Fig. 3c). In addition, statistically significant hypomethylation (FC -5.5) at a CpG island within the transcriptional start site of the Myc gene was observed in Subgroup 1, while a CpG island at the 5'-UTR of the PTCHD2 gene was significantly hypomethylated in Subgroup 2 (FC -5.1) (Online Resource 24). We also observed less overall methylation in the genome of patients with Myc activation (61\%) compared to those with implied Hh activation (39\%). These results suggest that variance in epigenic control of gene expression may contribute to observed subgroup differences in Myc and Hh signaling in the DIPG gene and protein expression profiles presented here.

\section{Methylation Analysis Based on Histone 3 Mutation}

Methylation patterns based on Histone 3 mutation status was inspected in DIPG, with focus on H3.3 as both gene and methylation data was available for only one H3.1 mutant specimen (Table 1). Analysis by H3.3 K27M mutation status revealed 1,449 differentially methylated CpG loci between H3.3 K27M mutant ( $\mathrm{n}=9$ ) and wild type specimens ( $\mathrm{n}=9$ ) (ANOVA, $p$ value $<0.05$ and FC $\leq 3$ or $\geq 3$, Online Resource 27). The H3.3 K27M mutation did appear to affect the genomic pattern of DNA methylation. The most prominent methylation dysregulation was observed in a number of biologically relevant genes (Online Resource 20; Online Resource 28). Hypomethylated genes in H3.3 mutant tumors included GATA2, a regulator of gene transcription; WNT3, a key factor in oncogenesis; $E V X 1$, an embryonic transcriptional repressor; $D L X 6 A S$, involved in forebrain and craniofacial development; and GDF6, a member of the bone morphogenetic protein (BMP) and TGF-beta families. Unsupervised analysis of DIPG tissue methylation profiles demonstrates clustering of H3.3 mutants, H3.1 mutants grouping together and within H3.3 wild types. H3.3 mutation-based supervised analysis using pairwise DIPG methylation profiles revealed differential methylation of $645 \mathrm{CpG}$ sites between H3.3 K27M mutant ( $\mathrm{n}=5$ ) and wild type ( $\mathrm{n}=4$ ) specimens, with 315 loci (48.8\%) hypomethylated in mutants, and 330 loci (51.2\%) hypomethylated in wild types (Online Resource 29). Of these, $212 \mathrm{CpG}$ sites exhibit the same methylation pattern in all subjects by H3F3A mutation status, with 134 loci (63.2\%) hypomethylated in mutant patients and 78 loci $(36.8 \%)$ hypomethylated in wild type patients $(n=4)$ (heat map and pathway depicted in Online Resource 30). No distinction was observed between the two H3.1 mutant DIPGs and the remaining two H3.3 wild type DIPGs in this analysis. The top biological function of genes selectively hypermethylated in mutants compared to wild type specimens was inhibition of autophagy of brain cancer cells ( $p$-values 9.54E-03), suggesting H3.3 K27M mutation may be associated with loss of inhibition of this process, resulting in increased tumor cell turnover (Online Resource 31).

\section{Discussion}

One major factor hindering our understanding of the biology DIPG is the paucity of specimens for molecular studies. Given this challenge, we sought to deepen the molecular characterization of this rare pediatric brain tumor by applying multiple cutting-edge analytic approaches to a cohort of DIPG and other pediatric brain tumor specimens. Here, we present the first comprehensive four-dimensional analysis of DIPG specimens that characterizes their proteomic, transcriptomic, methylomic, and Histone $\mathrm{H} 3$ mutation profiles. 
Pathways analysis of DIPG tumor tissue provides a window for greater understanding of DIPG as a distinct form of glioma. Overall, DIPG protein profiles were clearly distinct from other tumor types but most similar to other HGAs. Importantly, no significant difference was observed in the number of proteins identified in postmortem compared to intraoperatively acquired tissue specimens. The significant overlap (96\%) between proteome and transcriptome of DIPG specimens validates the utility of proteomic profiling for molecular characterization of DIPGs. Indeed, in two cases the extent of tissue mRNA degradation precluded gene expression analysis but proteomic analysis was still possible. Importantly, signaling pathways implicated through functional analysis of proteomic profiles are similar to those identified using gene expression profiles from the same patients, underscoring the utility of protein profiling for molecular characterization of DIPG.

Within our cohort, both protein and mRNA expression profiles suggested the presence of two molecular subtypes of DIPG, with differential expression of upstream regulatory molecules Myc Oncogene (N-Myc) and Glioma-associated oncogene (GLI1), a member of the Hedgehog (Hh) signaling pathway. Increased Hh signaling in brainstem gliomas as well as in DIPG stem cell-like progenitor cells has been previously reported [33,36]. Further, a recently constructed database of genomic analyses of pediatric DIPG specimens indicates copy number gains (75\%) at 12q14.1 corresponding to the GLII gene [5]. These findings indicate that Hh signaling, which drives the development of neural precursors in the ventral pons, may play an important role in tumor formation in a subset of DIPGs. In contrast, functional analysis of mRNA profiles from DIPG patients with decreased Hh pathway signaling (Subgroup 1) demonstrated relatively increased Myc activity (N-Myc) at both the mRNA and protein levels (Online Resource 15) which is consistent with previous findings of Myc amplification in brainstem glioma [3,5,36]. Recent studies also associated focal amplification of $M y c$ with a c.83A>T missense mutation of the histone $\mathrm{H} 3.3$ gene, H3F3A [26,27,45,57] which is consistent with our finding of increased $M Y C$ expression in four of five $H 3 F 3 A$ mutants (Online Resource 10). Slight differences in subgroup assignment between protein and gene data may be attributable to the relative instability or frequency of turnover of mRNA compared to proteins. In addition, the two tumor specimens whose mRNA and protein profiling implicated different molecular subgroups were normalized to frontal lobe, rather than perilesional normal brainstem tissue which may contain infiltrative tumor cells.

Increasing evidence points to epigenic forces in driving cancers including DIPGs [11,18,22]. Mutations in $H 3 F 3 A$ or the related $H I S T 1 H 3 B$, encoding Histone 3.3 and Histone 3.1, respectively, have been recently identified in up to $78 \%$ of pediatric DIPGs $[19,48,57]$. Conversion of a lysine residue to methionine at position 27 on Histone $\mathrm{H} 3$ results in loss of methylation and/or acetylation at this site, causing aberrant chromatin remodeling and gene expression [26,27,45,48,52,57] or loss of interaction with Polycomb repressive complex 2 (PRC2), a gene-silencing regulator [9,30,52]. We investigated the effect of the $\mathrm{H} 3.3$ and H3.1 mutation on molecular profiles of our DIPG cohort (62\% H3F3A and 20\% HISTIH3B mutants) and show global gene transcription upregulation associated with histone H3 K27M mutation. Since radiation is the major therapeutic modality used to treat children with DIPG, we questioned whether our H3 K27M cohort exhibited molecular pathways that could 
explain radiation therapy resistance. Functional analysis of DIPG mRNA and protein profiles demonstrated altered cell cycle control and inhibition of tumor cell autophagy pathways in H3 K27M mutants. Our results suggest that the H3 K27M mutation may potentially contribute to the resistance to radiation therapy and poorer overall prognosis seen in patients harboring this mutation by causing wide ranging alteration of epigenic mechanism [26,57]. Unfortunately, clinical data were not available for all patients in our cohort to correlate survival or age with Histone 3 mutation status, or with our identified Myc and Hh subtypes.

Another interesting observation in the mRNA and protein expression profiles of H3 K27M mutants include increased expression of HIPK1, which phosphorylates DAXX (deathdomain associated protein). DAXX is a subunit of H3.3-ATRX-DAXX chromatinremodeling complex required for $\mathrm{H} 3.3$ incorporation into heterochromatin and telomeres $[12,29]$. Somatic mutation of the ATRX-DAXX complex is associated with $31 \%$ of GBMs harboring the H3.3 K27M mutation and 100\% harboring the H3.3 G34R or G34V.3 mutation. HIPK1 upregulation could result in increased translocation of DAXX, which may in turn alter chromatin and telomere structure causing aberrant gene expression in DIPG.

Our observation of DIPG tumor hypomethylation compared to normal brainstem tissue is consistent with findings of global genomic hypomethylation in other cancers [11,13,23]. In general, DIPGs exhibit a more similar global methylation pattern to each other than to their corresponding normal peritumoral tissue. Differential methylation of genes related to the Myc and Hh pathways, concordant with observed differential expression at the mRNA and protein level, was also observed between DIPG Subgroups 1 and 2. This suggests that changes in DNA methylation may contribute to subgroup differences in Myc and $\mathrm{Hh}$ pathway expression observed in our DIPG cohort. Hypomethylation of $0^{6}$-methylguanine DNA methyltransferase (MGMT) in H3.3 mutants (Online Resources 29, 30) is of particular interest, as MGMT promoter methylation is associated with longer survival in GBM patients treated with the alkylating agent, temozolomide. Clinical trials investigating the efficacy of temozolomide in DIPG based on MGMT promotor status are currently underway; given our results, correlation with $\mathrm{H} 3.3 \mathrm{~K} 27 \mathrm{M}$ status may provide additional insight to patient response to this therapy. Our observation that neither H3.1 nor H3.3 K27M mutation status overlap with mRNA and protein data subgroups may imply that $\mathrm{Hh}$ and Myc pathways are secondary to (and independent of) the effects of histone 3 mutation. Given the small proportion of H3.1 K27M mutants in our cohort, meaningful comparisons of H3.3 vs. H3.1 methylation profiles could not be investigated.

Indeed, despite our multidimensional analyses of DIPG specimens, the relatively small sample size of this study is not sufficient to identify all possible DIPG subtypes. For example, identification of genetic subtypes of medulloblastoma was successful only upon inclusion of a large cohort of specimens [28,35,51]. Another factor that potentially may influence our molecular profiles is the heterogeneity of perilesional normal brain tissue. While normal tissue was identified via histopathological inspection by a neuropathologist, infiltrating tumor cells may be still present to varying degrees within the normal sections, contributing to the mRNA and protein pools. Despite these considerations, given the difference in relative Hh pathway activation observed in our DIPG cohort and the detection 
of related downstream molecules in our gene and protein profiles, our results do suggest that clinical identification of Hh signaling could be potentially used for patient stratification to pathway-targeted therapies.

Identification of CLU and TLN1 as proteins associated with DIPG is of special interest. CLU is a secreted molecular chaperone protein implicated in cancer $[15,17,31,42,54,55]$ that we previously detected in the CSF proteome of DIPG patients [43]. TLN1 is a cytoskeletal protein that controls integrin activation to facilitate cell migration by promoting cell motility and adhesion in glioma [7,40,41,46,56]. Currently, therapeutic agents targeting integrins such as Cilengitide are under investigation as a treatment for adult high-grade astrocytoma (GBM). Both CLU and TLN1 play a role in cytoskeletal formation, which is also pursued as a novel therapeutic target in glioma [7,10,40,44,50] (Online Resource 13). Given the continued controversy surrounding diagnostic biopsy for DIPG, identification of biologically relevant secreted tumor proteins such as CLU that may be detected in serially accessible fluids such as CSF, blood or urine could have significant clinical implications $[4,21,24,37]$.

In conclusion, DIPG is a devastating form of pediatric brain tumor for which no effective treatment exists. By integrating protein, mRNA, DNA methylation and histone H3 K27M mutation analysis, we provide a four-dimensional molecular characterization of DIPG to lend insight to tumor biology despite the paucity of tissue available for study. Our multidimensional analysis of rare DIPG specimens suggests that subtypes of DIPG may arise due to a complex interplay between epigenic factors and oncogenic signaling pathways. Importantly, we show that the DIPG proteome can contribute to our understanding this complex biology, and is useful to guide future research and improve molecular diagnosis and therapeutic design.

\title{
Supplementary Material
}

Refer to Web version on PubMed Central for supplementary material.

\section{Acknowledgments}

\author{
Funding: \\ Childhood Brain Tumor Foundation \\ Isabella Kerr Molina Foundation \\ Zickler Family Foundation \\ Musella Foundation \\ Brain Tumor Foundation for Children \\ The Sheikh Zayed Institute for Pediatric Surgical Innovation RAC Award \\ Clinical and Translational Science Institute (CTSI) Award (1UL1RR031988-01) \\ Intellectual and Developmental Disabilities Research Center (NICHD 5P30HD040677)
}


We would like to thank Dr. Kristy J. Brown for her kind assistance in collection and processing of proteomic mass spectrometry samples. The authors would like to thank all of the patients and families for donating tissue for this research. This manuscript is dedicated to the memory of Gabriella Miller.

\section{References}

1. Ajit, C.; Tamhane, DDD. Statistics and Data Analysis: From Elementary to Intermediate. Upper Saddle River, NJ: Prentice Hall; 2000.

2. Angelini P, Hawkins C, Laperriere N, Bouffet E, Bartels U. Post mortem examinations in diffuse intrinsic pontine glioma: challenges and chances. J Neurooncol. 2011; 101(1):75-81. [PubMed: 20473723]

3. Barrow J, Adamowicz-Brice M, Cartmill M, MacArthur D, Lowe J, Robson K, Brundler MA, Walker DA, Coyle B, Grundy R. Homozygous loss of ADAM3A revealed by genome-wide analysis of pediatric high-grade glioma and diffuse intrinsic pontine gliomas. Neuro Oncol. 2011; 13(2): 212-222. [PubMed: 21138945]

4. Bartels U, Hawkins C, Vezina G, Kun L, Souweidane M, Bouffet E. Proceedings of the diffuse intrinsic pontine glioma (DIPG) Toronto Think Tank: advancing basic and translational research and cooperation in DIPG. J Neurooncol. 2011; 105(1):119-125. [PubMed: 21901544]

5. Baudis M. Progenetix oncogenomic online resource. 2012 www.progenetix.net. . http:// www.progenetix.org/cgi-bin/projectsHome.cgi?project=DIPG.

6. Bax DA, Mackay A, Little SE, Carvalho D, Viana-Pereira M, Tamber N, Grigoriadis AE, Ashworth A, Reis RM, Ellison DW, Al-Sarraj S, Hargrave D, Jones C. A distinct spectrum of copy number aberrations in pediatric high-grade gliomas. Clin Cancer Res. 2010; 16(13):3368-3377. [PubMed: 20570930]

7. Belot N, Rorive S, Doyen I, Lefranc F, Bruyneel E, Dedecker R, Micik S, Brotchi J, Decaestecker C, Salmon I, Kiss R, Camby I. Molecular characterization of cell substratum attachments in human glial tumors relates to prognostic features. Glia. 2001; 36(3):375-390. [PubMed: 11746774]

8. Broniscer A, Baker JN, Baker SJ, Chi SN, Geyer JR, Morris EB, Gajjar A. Prospective collection of tissue samples at autopsy in children with diffuse intrinsic pontine glioma. Cancer. 2010; 116(19): 4632-4637. [PubMed: 20589749]

9. Chan KM, Fang D, Gan H, Hashizume R, Yu C, Schroeder M, Gupta N, Mueller S, James CD, Jenkins R, Sarkaria J, Zhang Z. The histone H3.3K27M mutation in pediatric glioma reprograms H3K27 methylation and gene expression. Genes Dev. 2013

10. Chen D, Wang Y, Zhang K, Jiao X, Yan B, Liang J. Antisense oligonucleotide against clusterin regulates human hepatocellular carcinoma invasion through transcriptional regulation of matrix metalloproteinase-2 and e-cadherin. Int J Mol Sci. 2012; 13(8):10594-10607. [PubMed: 22949882]

11. Dawson MA, Kouzarides T. Cancer epigenetics: from mechanism to therapy. Cell. 2012; 150(1): 12-27. [PubMed: 22770212]

12. Dhayalan A, Tamas R, Bock I, Tattermusch A, Dimitrova E, Kudithipudi S, Ragozin S, Jeltsch A. The ATRX-ADD domain binds to $\mathrm{H} 3$ tail peptides and reads the combined methylation state of K4 and K9. Hum Mol Genet. 2011; 20(11):2195-2203. [PubMed: 21421568]

13. Ehrlich M, Lacey M. DNA hypomethylation and hemimethylation in cancer. Adv Exp Med Biol. 2013; 754:31-56. [PubMed: 22956495]

14. Eisenhart C. The assumptions underlying the analysis of variance. Biometrics. 1947; 1(3):1-21. [PubMed: 20240414]

15. Ekici AI, Eren B, Turkmen N, Comunoglu N, Fedakar R. Clusterin expression in nonneoplastic adenohypophyses and pituitary adenomas: cytoplasmic clusterin localization in adenohypophysis is related to aging. Endocr Pathol. 2008; 19(1):47-53. [PubMed: 18239862]

16. Frazier JL, Lee J, Thomale UW, Noggle JC, Cohen KJ, Jallo GI. Treatment of diffuse intrinsic brainstem gliomas: failed approaches and future strategies. J Neurosurg Pediatr. 2009; 3(4):259_ 269. [PubMed: 19338403]

17. Fu Y, Lai Y, Wang Q, Liu X, He W, Zhang H, Fan C, Yang G. Overexpression of clusterin promotes angiogenesis via the vascular endothelial growth factor in primary ovarian cancer. Mol Med Rep. 2013 
18. Fullgrabe J, Kavanagh E, Joseph B. Histone onco-modifications. Oncogene. 2011; 30(31):33913403. [PubMed: 21516126]

19. Gielen GH, Gessi M, Hammes J, Kramm CM, Waha A, Pietsch T. H3F3A K27M mutation in pediatric CNS tumors: a marker for diffuse high-grade astrocytomas. Am J Clin Pathol. 2013; 139(3):345-349. [PubMed: 23429371]

20. Gilbertson RJ, Hill DA, Hernan R, Kocak M, Geyer R, Olson J, Gajjar A, Rush L, Hamilton RL, Finkelstein SD, Pollack IF. ERBB1 is amplified and overexpressed in highgrade diffusely infiltrative pediatric brain stem glioma. Clin Cancer Res. 2003; 9(10 Pt 1):3620-3624. [PubMed: 14506149]

21. Hankinson TC, Campagna EJ, Foreman NK, Handler MH. Interpretation of magnetic resonance images in diffuse intrinsic pontine glioma: a survey of pediatric neurosurgeons. J Neurosurg Pediatr. 2011; 8(1):97-102. [PubMed: 21721895]

22. Herranz M, Esteller M. DNA methylation and histone modifications in patients with cancer: potential prognostic and therapeutic targets. Methods in molecular biology. 2007; 361:25-62. [PubMed: 17172706]

23. Hon GC, Hawkins RD, Caballero OL, Lo C, Lister R, Pelizzola M, Valsesia A, Ye Z, Kuan S, Edsall LE, Camargo AA, Stevenson BJ, Ecker JR, Bafna V, Strausberg RL, Simpson AJ, Ren B. Global DNA hypomethylation coupled to repressive chromatin domain formation and gene silencing in breast cancer. Genome Res. 2012; 22(2):246-258. [PubMed: 22156296]

24. Jansen MH, van Vuurden DG, Vandertop WP, Kaspers GJ. Diffuse intrinsic pontine gliomas: a systematic update on clinical trials and biology. Cancer Treat Rev. 2012; 38(1):27-35. [PubMed: 21764221]

25. Khan AA, Dace DS, Ryazanov AG, Kelly J, Apte RS. Resveratrol regulates pathologic angiogenesis by a eukaryotic elongation factor-2 kinase-regulated pathway. Am J Pathol. 2010; 177(1):481-492. [PubMed: 20472894]

26. Khuong-Quang DA, Buczkowicz P, Rakopoulos P, Liu XY, Fontebasso AM, Bouffet E, Bartels U, Albrecht S, Schwartzentruber J, Letourneau L, Bourgey M, Bourque G, Montpetit A, Bourret G, Lepage P, Fleming A, Lichter P, Kool M, von Deimling A, Sturm D, Korshunov A, Faury D, Jones DT, Majewski J, Pfister SM, Jabado N, Hawkins C. K27M mutation in histone H3.3 defines clinically and biologically distinct subgroups of pediatric diffuse intrinsic pontine gliomas. Acta Neuropathol. 2012; 124(3):439-447. [PubMed: 22661320]

27. Khuong-Quang DA, Gerges N, Jabado N. [Mutations in histone H3.3 and chromatin remodeling genes drive pediatric and young adult glioblastomas]. Med Sci (Paris). 2012; 28(10):809-812. [PubMed: 23067407]

28. Kool M, Korshunov A, Remke M, Jones DT, Schlanstein M, Northcott PA, Cho YJ, Koster J, Schouten-van Meeteren A, van Vuurden D, Clifford SC, Pietsch T, von Bueren AO, Rutkowski S, McCabe M, Collins VP, Backlund ML, Haberler C, Bourdeaut F, Delattre O, Doz F, Ellison DW, Gilbertson RJ, Pomeroy SL, Taylor MD, Lichter P, Pfister SM. Molecular subgroups of medulloblastoma: an international meta-analysis of transcriptome, genetic aberrations, and clinical data of WNT, SHH, Group 3, and Group 4 medulloblastomas. Acta Neuropathol. 2012; 123(4): 473-484. [PubMed: 22358457]

29. Lewis PW, Elsaesser SJ, Noh KM, Stadler SC, Allis CD. Daxx is an H3.3-specific histone chaperone and cooperates with ATRX in replication-independent chromatin assembly at telomeres. Proc Natl Acad Sci U S A. 2010; 107(32):14075-14080. [PubMed: 20651253]

30. Lewis PW, Muller MM, Koletsky MS, Cordero F, Lin S, Banaszynski LA, Garcia BA, Muir TW, Becher OJ, Allis CD. Inhibition of PRC2 Activity by a Gain-of-Function H3 Mutation Found in Pediatric Glioblastoma. Science. 2013

31. Ling IF, Bhongsatiern J, Simpson JF, Fardo DW, Estus S. Genetics of clusterin isoform expression and Alzheimer's disease risk. PLoS One. 2012; 7(4):e33923. [PubMed: 22506010]

32. Mace EM, Zhang J, Siminovitch KA, Takei F. Elucidation of the integrin LFA-1-mediated signaling pathway of actin polarization in natural killer cells. Blood. 2010; 116(8):1272-1279. [PubMed: 20472831]

33. Monje M, Mitra SS, Freret ME, Raveh TB, Kim J, Masek M, Attema JL, Li G, Haddix T, Edwards MS, Fisher PG, Weissman IL, Rowitch DH, Vogel H, Wong AJ, Beachy PA. Hedgehog- 
responsive candidate cell of origin for diffuse intrinsic pontine glioma. Proc Natl Acad Sci U S A. 2011; 108(11):4453-4458. [PubMed: 21368213]

34. Nazarian J, Santi M, Hathout Y, Macdonald TJ. Protein profiling of formalin fixed paraffin embedded tissue: Identification of potential biomarkers for pediatric brainstem glioma. Proteomics Clin Appl. 2008; 2(6):915-924. [PubMed: 21136889]

35. Northcott PA, Korshunov A, Witt H, Hielscher T, Eberhart CG, Mack S, Bouffet E, Clifford SC, Hawkins CE, French P, Rutka JT, Pfister S, Taylor MD. Medulloblastoma comprises four distinct molecular variants. J Clin Oncol. 2011; 29(11):1408-1414. [PubMed: 20823417]

36. Paugh BS, Qu C, Jones C, Liu Z, Adamowicz-Brice M, Zhang J, Bax DA, Coyle B, Barrow J, Hargrave D, Lowe J, Gajjar A, Zhao W, Broniscer A, Ellison DW, Grundy RG, Baker SJ. Integrated molecular genetic profiling of pediatric high-grade gliomas reveals key differences with the adult disease. J Clin Oncol. 2010; 28(18):3061-3068. [PubMed: 20479398]

37. Perez-Gomez JL, Rodriguez-Alvarez CA, Marhx-Bracho A, Rueda-Franco F. Stereotactic biopsy for brainstem tumors in pediatric patients. Childs Nerv Syst. 2010; 26(1):29-34. [PubMed: 19784659]

38. Puget S, Philippe C, Bax DA, Job B, Varlet P, Junier MP, Andreiuolo F, Carvalho D, Reis R, Guerrini-Rousseau L, Roujeau T, Dessen P, Richon C, Lazar V, Le Teuff G, Sainte-Rose C, Geoerger B, Vassal G, Jones C, Grill J. Mesenchymal transition and PDGFRA amplification/ mutation are key distinct oncogenic events in pediatric diffuse intrinsic pontine gliomas. PLoS One. 2012; 7(2):e30313. [PubMed: 22389665]

39. Qureshi AH, Chaoji V, Maiguel D, Faridi MH, Barth CJ, Salem SM, Singhal M, Stoub D, Krastins B, Ogihara M, Zaki MJ, Gupta V. Proteomic and phospho-proteomic profile of human platelets in basal, resting state: insights into integrin signaling. PLoS One. 2009; 4(10):e7627. [PubMed: 19859549]

40. Rao Malla R, Gopinath S, Alapati K, Gorantla B, Gondi CS, Rao JS. Knockdown of cathepsin B and uPAR inhibits CD151 and alpha3beta1 integrin-mediated cell adhesion and invasion in glioma. Mol Carcinog. 2012

41. Ratnikov BI, Partridge AW, Ginsberg MH. Integrin activation by talin. J Thromb Haemost. 2005; 3(8):1783-1790. [PubMed: 16102045]

42. Redondo M, Villar E, Torres-Munoz J, Tellez T, Morell M, Petito CK. Overexpression of clusterin in human breast carcinoma. Am J Pathol. 2000; 157(2):393-399. [PubMed: 10934144]

43. Saratsis AM, Yadavilli S, Magge S, Rood BR, Perez J, Hill DA, Hwang E, Kilburn L, Packer RJ, Nazarian J. Insights into pediatric diffuse intrinsic pontine glioma through proteomic analysis of cerebrospinal fluid. Neuro Oncol. 2012; 14(5):547-560. [PubMed: 22492959]

44. Scaringi C, Minniti G, Caporello P, Enrici RM. Integrin inhibitor cilengitide for the treatment of glioblastoma: a brief overview of current clinical results. Anticancer Res. 2012; 32(10):42134223. [PubMed: 23060541]

45. Schwartzentruber J, Korshunov A, Liu XY, Jones DT, Pfaff E, Jacob K, Sturm D, Fontebasso AM, Quang DA, Tonjes M, Hovestadt V, Albrecht S, Kool M, Nantel A, Konermann C, Lindroth A, Jager N, Rausch T, Ryzhova M, Korbel JO, Hielscher T, Hauser P, Garami M, Klekner A, Bognar L, Ebinger M, Schuhmann MU, Scheurlen W, Pekrun A, Fruhwald MC, Roggendorf W, Kramm C, Durken M, Atkinson J, Lepage P, Montpetit A, Zakrzewska M, Zakrzewski K, Liberski PP, Dong Z, Siegel P, Kulozik AE, Zapatka M, Guha A, Malkin D, Felsberg J, Reifenberger G, von Deimling A, Ichimura K, Collins VP, Witt H, Milde T, Witt O, Zhang C, Castelo-Branco P, Lichter P, Faury D, Tabori U, Plass C, Majewski J, Pfister SM, Jabado N. Driver mutations in histone H3.3 and chromatin remodelling genes in paediatric glioblastoma. Nature. 2012; 482(7384):226-231. [PubMed: 22286061]

46. Sen S, Ng WP, Kumar S. Contributions of talin-1 to glioma cell-matrix tensional homeostasis. J R Soc Interface. 2012; 9(71):1311-1317. [PubMed: 22158841]

47. Sharma S, Free A, Mei Y, Peiper SC, Wang Z, Cowell JK. Distinct molecular signatures in pediatric infratentorial glioblastomas defined by aCGH. Exp Mol Pathol. 2010; 89(2):169-174. [PubMed: 20621092]

48. Sturm D, Witt H, Hovestadt V, Khuong-Quang DA, Jones DT, Konermann C, Pfaff E, Tonjes M, Sill M, Bender S, Kool M, Zapatka M, Becker N, Zucknick M, Hielscher T, Liu XY, Fontebasso AM, Ryzhova M, Albrecht S, Jacob K, Wolter M, Ebinger M, Schuhmann MU, van Meter T, 
Fruhwald MC, Hauch H, Pekrun A, Radlwimmer B, Niehues T, von Komorowski G, Durken M, Kulozik AE, Madden J, Donson A, Foreman NK, Drissi R, Fouladi M, Scheurlen W, von Deimling A, Monoranu C, Roggendorf W, Herold-Mende C, Unterberg A, Kramm CM, Felsberg J, Hartmann C, Wiestler B, Wick W, Milde T, Witt O, Lindroth AM, Schwartzentruber J, Faury D, Fleming A, Zakrzewska M, Liberski PP, Zakrzewski K, Hauser P, Garami M, Klekner A, Bognar L, Morrissy S, Cavalli F, Taylor MD, van Sluis P, Koster J, Versteeg R, Volckmann R, Mikkelsen T, Aldape K, Reifenberger G, Collins VP, Majewski J, Korshunov A, Lichter P, Plass C, Jabado $\mathrm{N}$, Pfister SM. Hotspot mutations in H3F3A and IDH1 define distinct epigenetic and biological subgroups of glioblastoma. Cancer Cell. 2012; 22(4):425-437. [PubMed: 23079654]

49. Sufit A, Donson AM, Birks DK, Knipstein JA, Fenton LZ, Jedlicka P, Hankinson TC, Handler MH, Foreman NK. Diffuse intrinsic pontine tumors: a study of primitive neuroectodermal tumors versus the more common diffuse intrinsic pontine gliomas. J Neurosurg Pediatr. 2012; 10(2):8188. [PubMed: 22747092]

50. Tabatabai G, Weller M, Nabors B, Picard M, Reardon D, Mikkelsen T, Ruegg C, Stupp R. Targeting integrins in malignant glioma. Target Oncol. 2010; 5(3):175-181. [PubMed: 20820929]

51. Taylor MD, Northcott PA, Korshunov A, Remke M, Cho YJ, Clifford SC, Eberhart CG, Parsons DW, Rutkowski S, Gajjar A, Ellison DW, Lichter P, Gilbertson RJ, Pomeroy SL, Kool M, Pfister SM. Molecular subgroups of medulloblastoma: the current consensus. Acta Neuropathol. 2012; 123(4):465-472. [PubMed: 22134537]

52. Venneti S, Garimella MT, Sullivan LM, Martinez D, Huse JT, Heguy A, Santi M, Thompson CB, Judkins AR. Evaluation of Histone 3 Lysine 27 Trimethylation (H3K27me3) and Enhancer of Zest 2 (EZH2) in Pediatric Glial and Glioneuronal Tumors Shows Decreased H3K27me3 in H3F3A K27M Mutant Glioblastomas. Brain Pathol. 2013

53. Walker DA, Punt JA, Sokal M. Clinical management of brain stem glioma. Arch Dis Child. 1999; 80(6):558-564. [PubMed: 10332008]

54. Wang C, Jiang K, Kang X, Gao D, Sun C, Li Y, Sun L, Zhang S, Liu X, Wu W, Yang P, Guo K, Liu Y. Tumor-derived secretory clusterin induces epithelial-mesenchymal transition and facilitates hepatocellular carcinoma metastasis. Int J Biochem Cell Biol. 2012; 44(12):2308-2320. [PubMed: 23010347]

55. Wang Y, Wang X, Zhao H, Liang B, Du Q. Clusterin confers resistance to TNF-alphainduced apoptosis in breast cancer cells through NF-kappaB activation and Bcl-2 overexpression. J Chemother. 2012; 24(6):348-357. [PubMed: 23174100]

56. Wegener KL, Partridge AW, Han J, Pickford AR, Liddington RC, Ginsberg MH, Campbell ID. Structural basis of integrin activation by talin. Cell. 2007; 128(1):171-182. [PubMed: 17218263]

57. Wu G, Broniscer A, McEachron TA, Lu C, Paugh BS, Becksfort J, Qu C, Ding L, Huether R, Parker M, Zhang J, Gajjar A, Dyer MA, Mullighan CG, Gilbertson RJ, Mardis ER, Wilson RK, Downing JR, Ellison DW, Baker SJ. Somatic histone H3 alterations in pediatric diffuse intrinsic pontine gliomas and non-brainstem glioblastomas. Nat Genet. 2012; 44(3):251-253. [PubMed: 22286216]

58. Zarghooni M, Bartels U, Lee E, Buczkowicz P, Morrison A, Huang A, Bouffet E, Hawkins C. Whole-genome profiling of pediatric diffuse intrinsic pontine gliomas highlights platelet-derived growth factor receptor alpha and poly (ADP-ribose) polymerase as potential therapeutic targets. J Clin Oncol. 2010; 28(8):1337-1344. [PubMed: 20142589] 
a

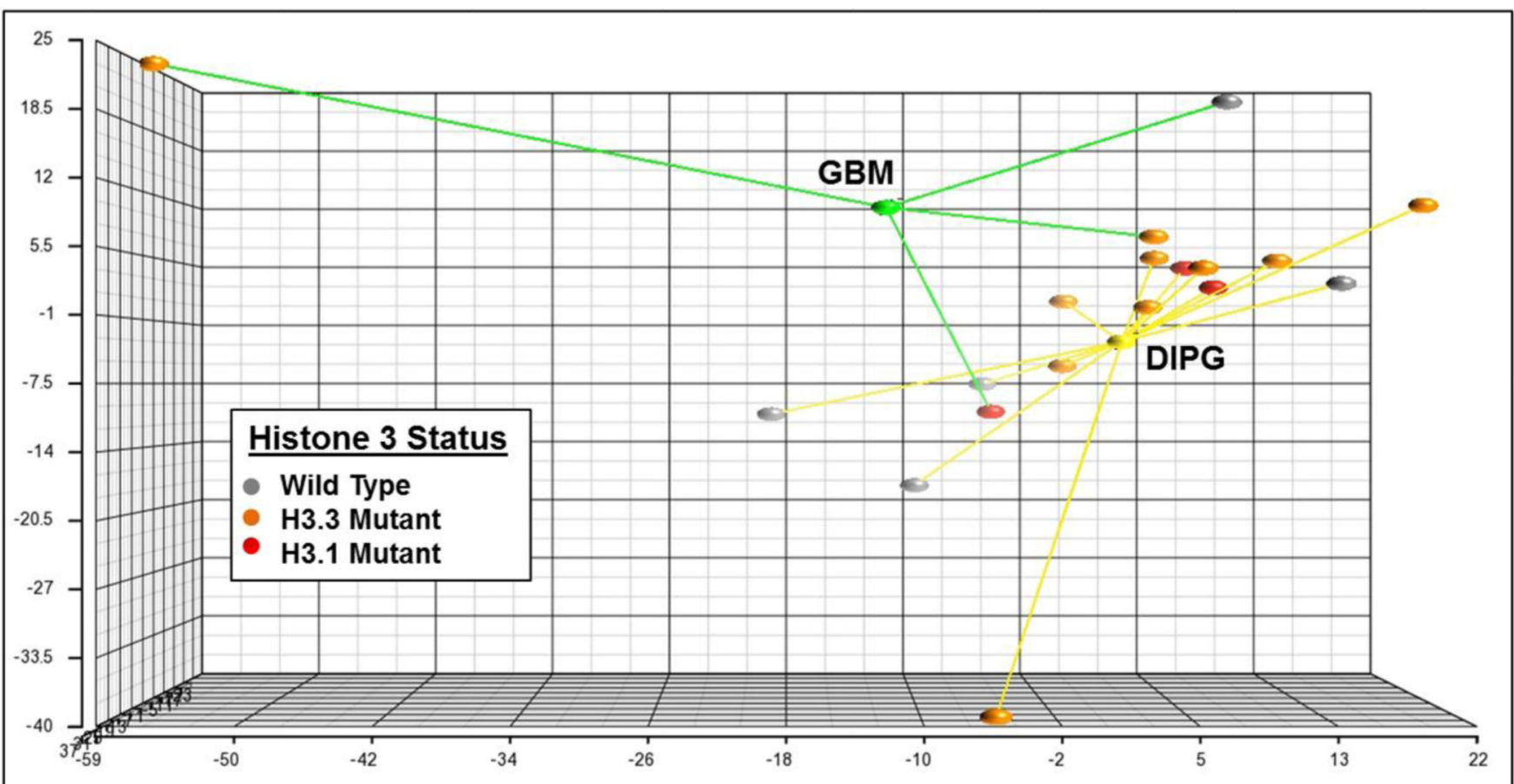


b
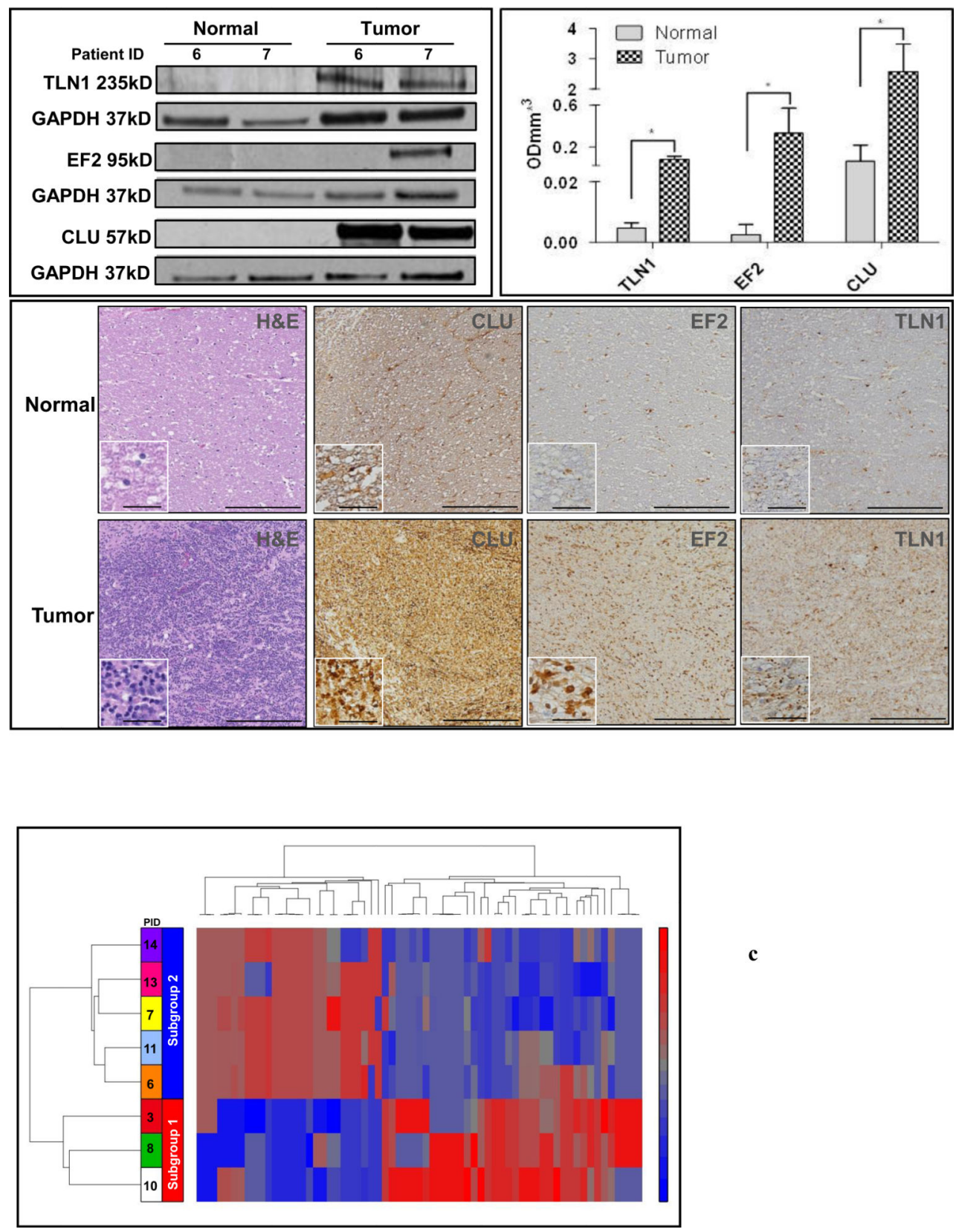


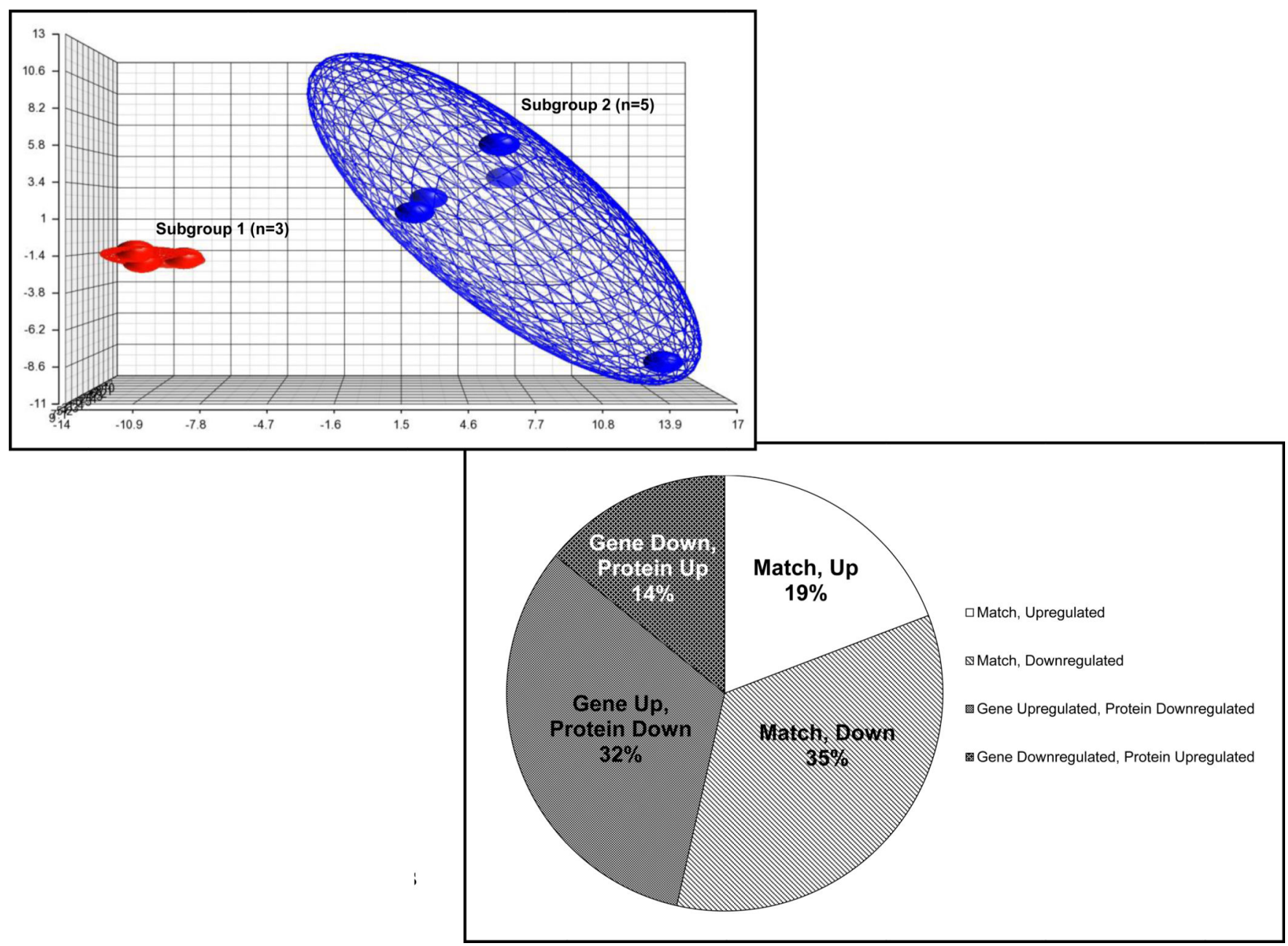

Fig. 1. Protein and mRNA profiles of DIPGs are Distinct from other Pediatric Brain Tumors and Exhibit Two Molecular Subtypes

1a Principal component analysis of high-grade astrocytoma protein expression values (DIPG $\mathrm{n}=14$, Yellow; pediatric supratentorial GBM n=4, Green) demonstrates unique protein profiles by tumor location and Histone $3 \mathrm{~K} 27 \mathrm{M}$ mutation status (H3.1 Red, H3.3 Orange, H3 wild type Gray). H3 mutant DIPGs cluster closely compared to H3 wild type or GBMs.

1b Top Left Panel Western blot analysis of DIPG and normal tissue lysate reveals tumorspecific expression of Talin-1 (TLN1), Eukaryotic Elongation Factor 2 (EF2) and Clusterin (CLU), with GAPDH was used as a loading control

1b Top Right Panel Protien expression levels were measured by densitometry: average values for each group (tumor and normal) are represented by bar graphs. $*=p$-value $<0.05$

1b Bottom Panel Immunohistochemical staining of DIPG tumor and adjacent normal brainstem tissue (Patient ID 7) validated cytosolic upregulation of TLN1, EF2 and CLU in tumor regions as indicated by $\mathrm{H} \& \mathrm{E}$ staining. Scale bar $=200 \mu \mathrm{m}$; Inset scale bar $=25 \mu \mathrm{m}$ 1cTop Panel Supervised hierarchical clustering of DIPG tumor protein expression profiles ( $n=8$ pairs, pairwise tumor vs. normal FC values) based on subgroups identified through mRNA expression profile analysis revealed 65 significantly differentially expressed proteins between Subgroup 1 and 2 (ANOVA, $p$-value $<0.05$ and FC $\leq 2$ or $\geq 2$ ) 
1c Middle Panel Principal component analysis after unsupervised hierarchical clustering of DIPG mRNA expression profiles depicts two distinct subgroups with differential expression of 1,918 genes ( $n=8$ pairs, pairwise tumor vs. normal FC $\leq 2$ or $\geq 2$ ). Subgroup $1=\operatorname{Red}, n=3$, Patient IDs 3, 8 and 10; Subgroup 2=Blue, n=5, PIDs 6, 7, 11, 13 and 14

1c Bottom Panel Overall concordance between mRNA and protein expression profiles is seen across $53 \%$ of molecules detected 
a

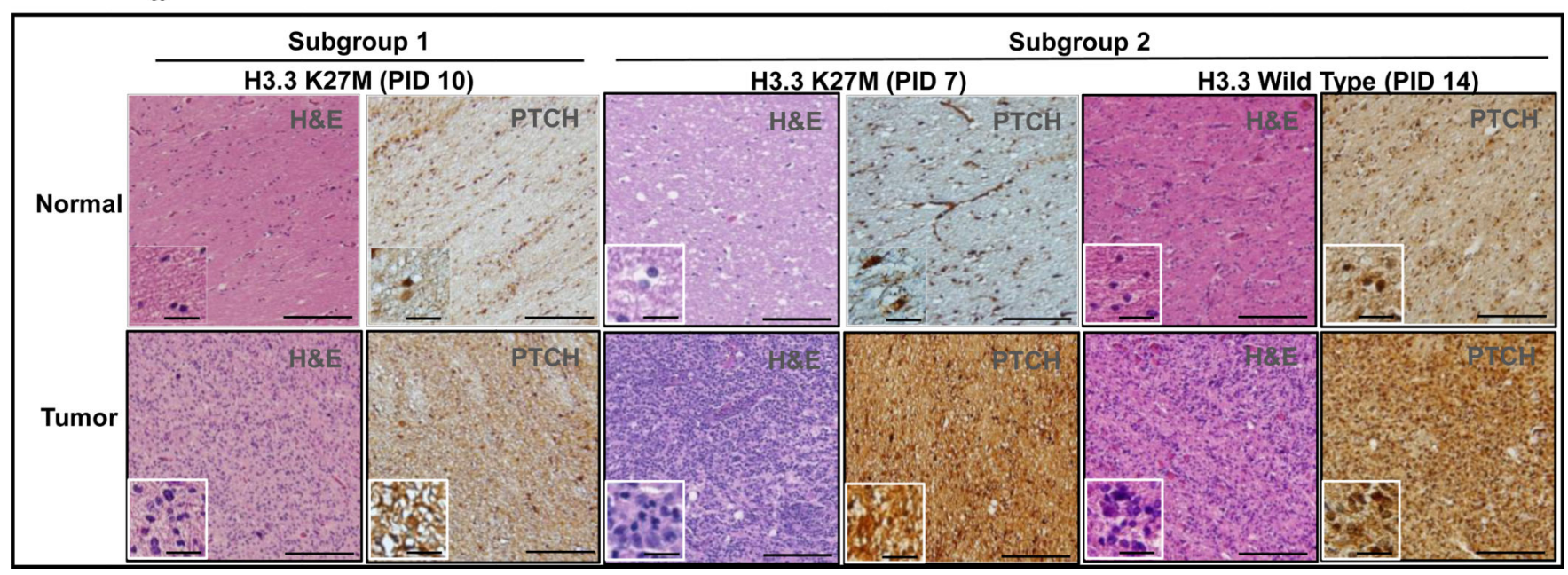




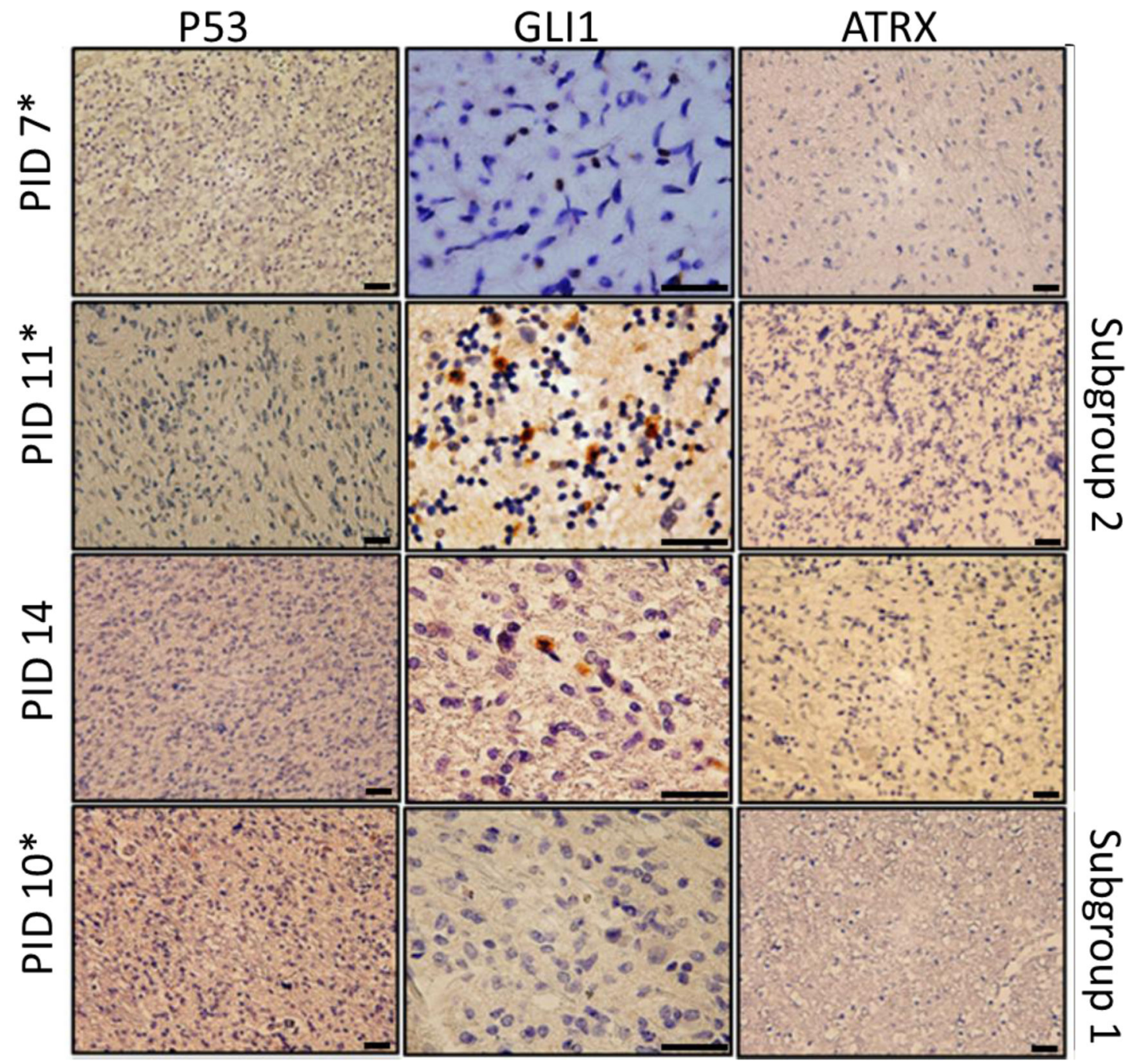

Fig. 2. Molecular Expression in Tumor Tissue Validates Differential Hh Signaling Between DIPG Subgroups

2a Immunohistochemical staining of DIPG tumor and normal tissue demonstrates increased PTCH staining in DIPG tumor tissue from patients with implicated Hh signaling (center and right, Patient IDs 7 and 14). Patients with implicated Myc signaling (left, Patient ID 10) demonstrate a relative decrease in PTCH staining. H3.3 mutation status does not appear to

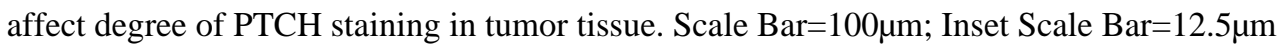
2b Immunohistochemical staining of DIPG tumor tissue $(n=4)$ demonstrates nuclear localization of GLI1 in patients with implicated Hh signaling (Subgroup 2, PIDs 7, 11, 14), and low levels of p53 expression in all $\mathrm{H} 3$ mutants tested (denoted by *). H3 mutation does not appear to affect degree of GLI1 staining in tumor tissue. ATRX expression was not detected in DIPG specimens. Scale Bar $=3 \mu \mathrm{m}$ for P53 and ATRX and $90 \mu \mathrm{m}$ for GLI1 
a

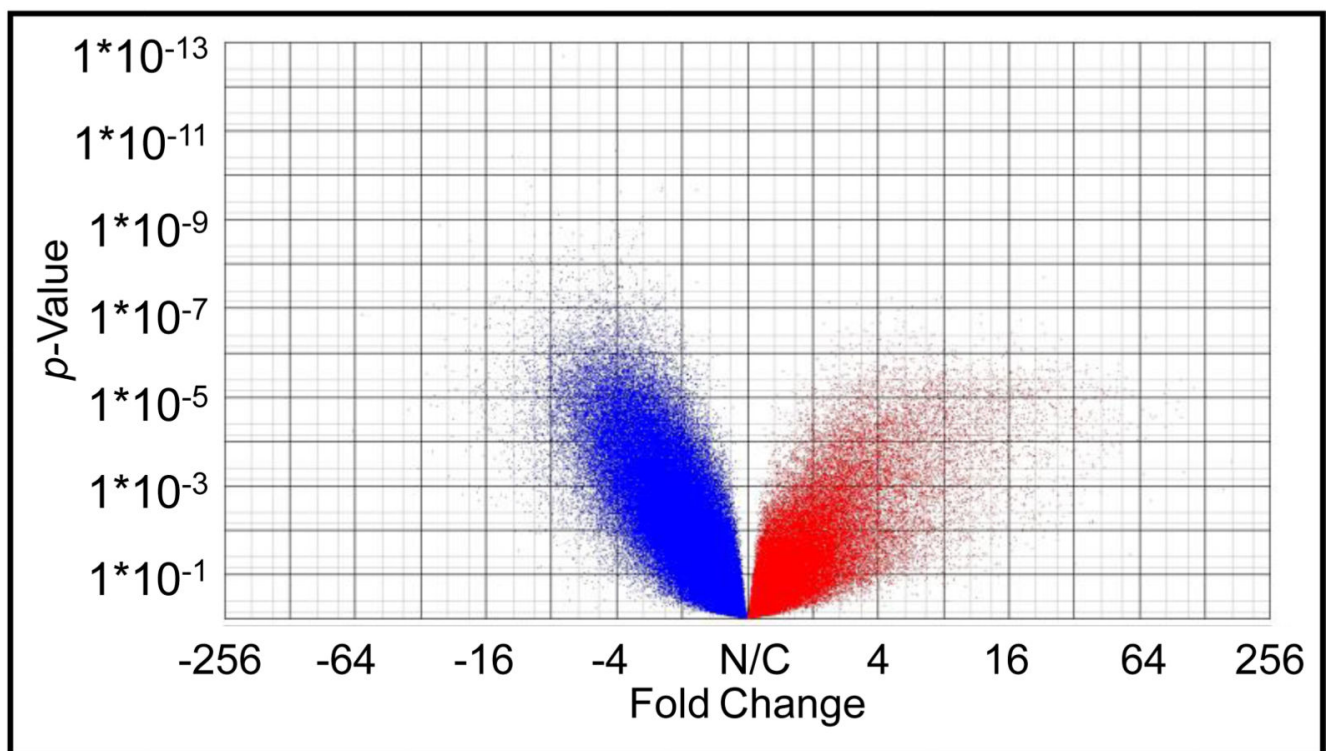

b

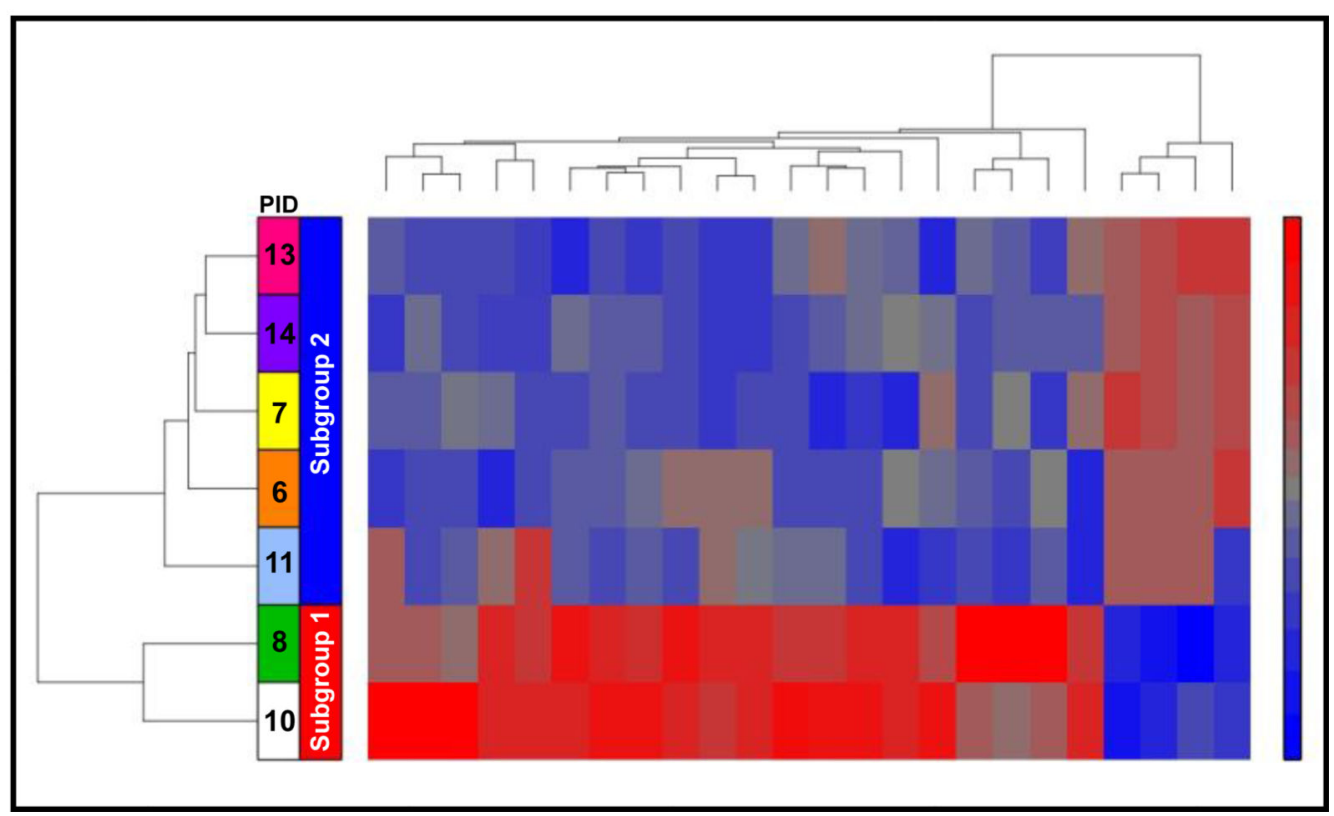




\section{C}

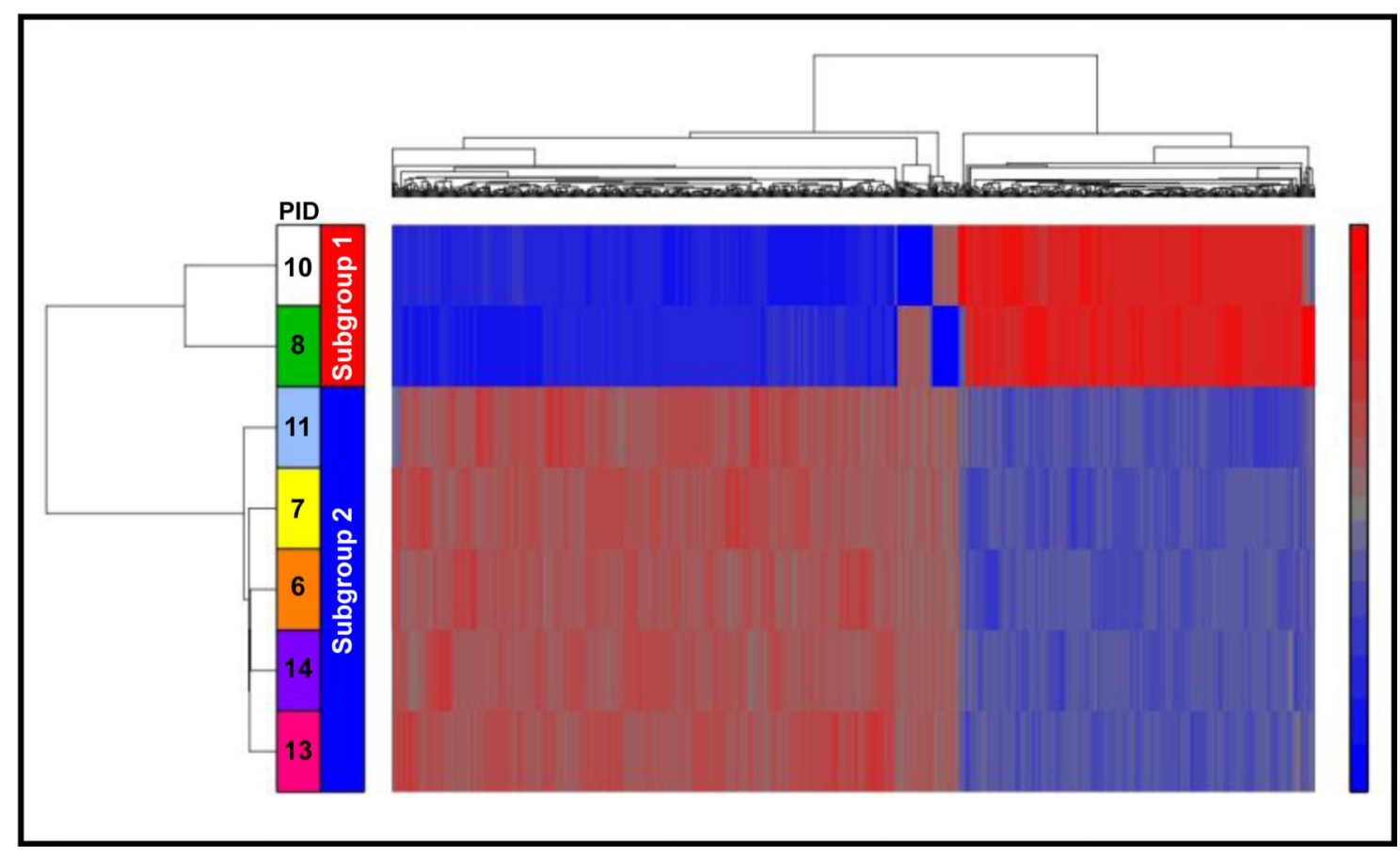

Fig. 3. Patterns of DNA Methylation in DIPG Tissue

3a Analysis of DNA methylation profiles of all DIPG specimens (fold change of average methylation in tumor compared to normal) demonstrates global DNA hypomethylation in tumor ( $\mathrm{n}=9$ ) compared normal brainstem tissue specimens ( $\mathrm{n}=9$ ). Volcano plot depicts 4,808 hypermethylated (red) and 14,428 hypomethylated (blue) $\mathrm{CpG}$ sites in tumor relative to normal tissue specimens (ANOVA, $p$-value with FDR $<0.05$ and FC $\leq 3$ or $\geq 3$ ). Xaxis=Tumor vs. Normal Fold Change value. $\mathrm{Y}$-axis $=p$-value 3b Unsupervised analysis of DNA methylation profiles at $486 \mathrm{CpG}$ loci related to genes belonging to Myc and Hh signaling pathways in patients in whom mRNA analysis was also performed $(\mathrm{n}=6)$ identified statistically significant differential methylation of 29 genes between DIPG Subgroup 1 and 2 (ANOVA, $p$-value $<0.05$ and FC $\leq 2$ or $\geq 2$ )

$3 c$ Comparison of whole genome DNA methylation profiles supervised by molecular subgroup ( $\mathrm{n}=7$ pairs, pairwise tumor vs. normal fold change values) revealed an additional 786 differentially methylated sites between DIPG Subgroup 1 and 2 (ANOVA, $p$-value $<0.05$ and $\mathrm{FC} \leq 3$ or $\geq 3$ ). Functional analysis of this data set identified dysregulated genes related to Myc, WNT, and Hh signaling pathways and network interaction with Histone 3 


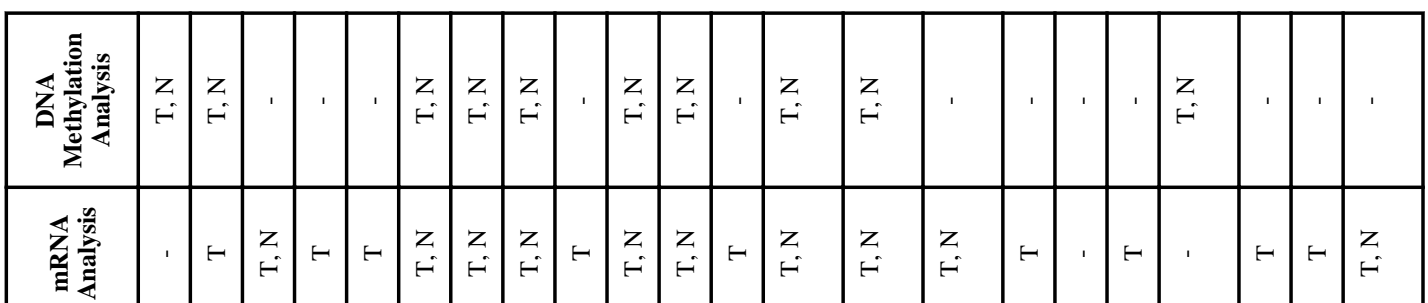

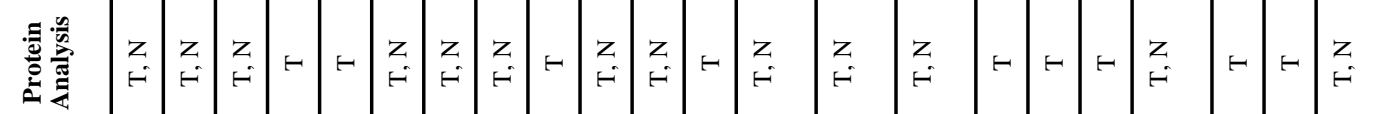

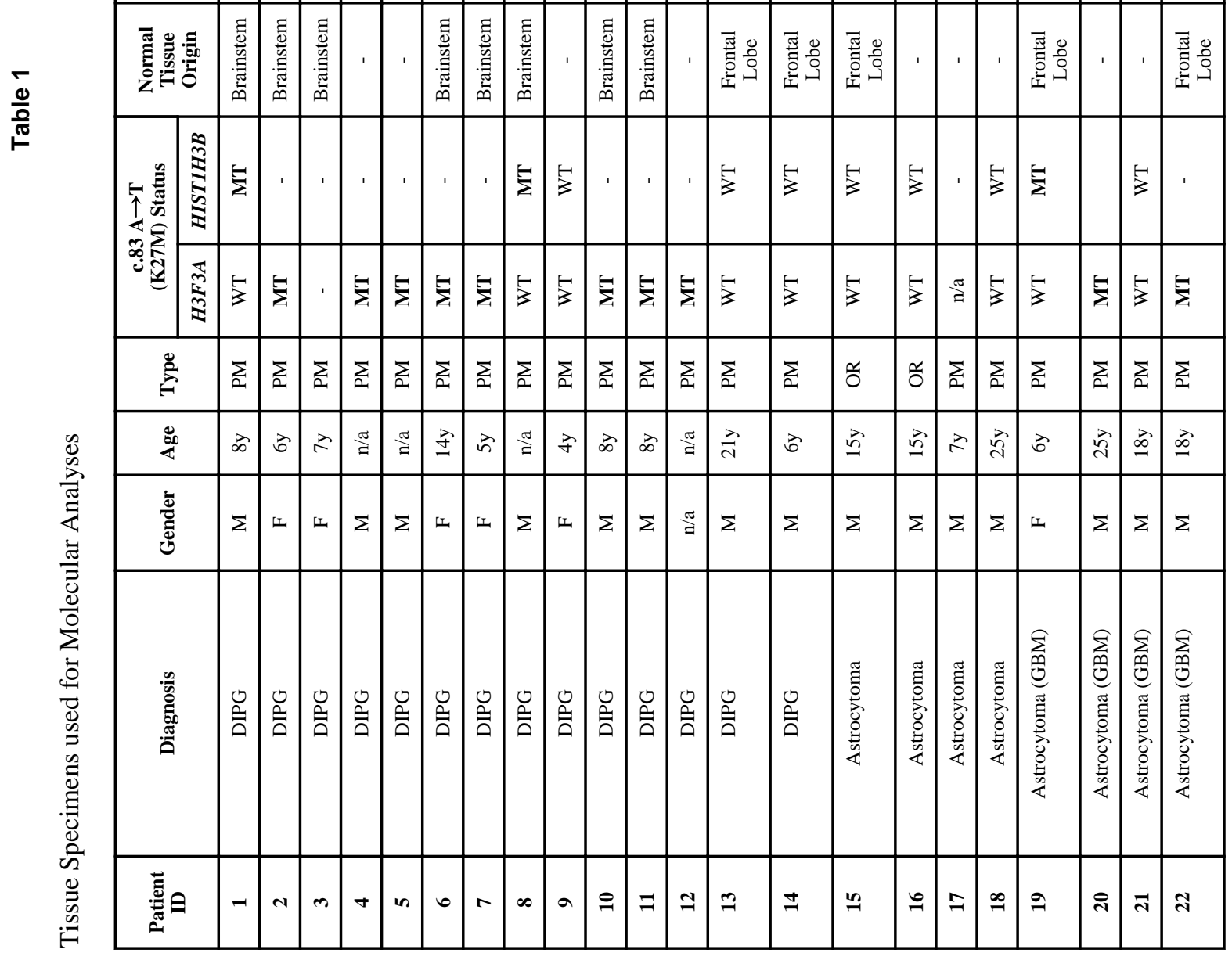




\begin{tabular}{|c|c|c|c|c|c|c|c|c|c|c|}
\hline 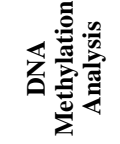 & & & & & & ' & ' & ' & ' & $\varrho$ \\
\hline 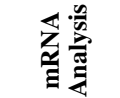 & $r$ & H & $r$ & H & $r$ & $H$ & $r$ & $H$ & $H$ & $\stackrel{\infty}{\sim}$ \\
\hline 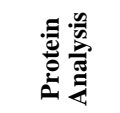 & $H$ & H & $r$ & H & $\mathrm{H}$ & $\mathrm{H}$ & $\mapsto$ & $H$ & H & $\bar{m}$ \\
\hline 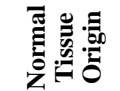 & & ' & ' & ' & & ' & ' & ' & ' & 9 \\
\hline 寉总 & & ' & ' & ' & & ' & ' & ' & ' & $\varrho$ \\
\hline 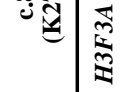 & 5 & $\xi$ & 5 & 5 & 5 & 5 & 5 & 5 & 5 & ते \\
\hline 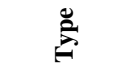 & ô & $\sum$ & ๘ै & 。ㅇ & ๘ै & 。ै & 。ै & $\sum_{\Sigma}$ & ซै & \\
\hline 总 & $\vec{n}$ & $\vec{\lambda}$ & $\vec{m}$ & $\stackrel{n}{n}$ & $\Xi$ & $\stackrel{2}{n}$ & $\vec{\infty}$ & ৯ & $\triangleq$ & $\bar{m}$ \\
\hline 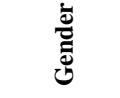 & $\Sigma$ & $\Sigma$ & $\Sigma$ & $\Sigma$ & $\Sigma$ & $\Sigma$ & 山 & 山 & L & \\
\hline 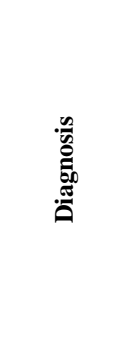 & 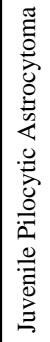 & 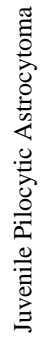 & 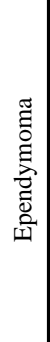 & 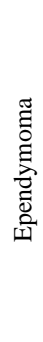 & 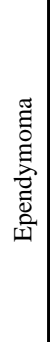 & 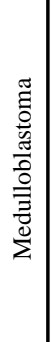 & 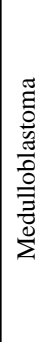 & 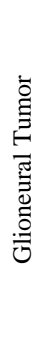 & 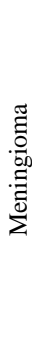 & 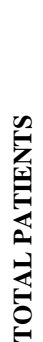 \\
\hline 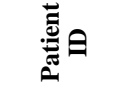 & $\ddot{\lambda}$ & $\mathbb{\lambda}$ & $\mathbb{2}$ & i & 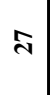 & $\stackrel{\infty}{\sim}$ & ते & లి & $\bar{m}$ & \\
\hline
\end{tabular}

Acta Neuropathol. Author manuscript; available in PMC 2015 June 01. 